ISSN = 1980-993X - doi:10.4136/1980-993X
www.agro.unitau.br/ambi-agua
E-mail: ambi-agua@agro.unitau.br
Tel.: (12) 3625-4116

\title{
Vulnerabilidade de sub-bacias hidrográficas por meio da equação universal de perda de solo e da integração de parâmetros morfométricos, topográficos, hidrológicos e de uso/cobertura da terra no estado do Rio de Janeiro, Brasil
} (doi:10.4136/ambi-agua.76)

\author{
Thomaz Correa e Castro da Costa ${ }^{1}$; Elaine Cristina Cardoso Fidalgo ${ }^{\mathbf{1}}$; Uebi Jorge \\ Naime $^{1}$; Saulo Pedrinha Guimarães ${ }^{2}$; Maria José Zaroni ${ }^{1}$; Mariella Camardelli Uzeda ${ }^{3}$ \\ ${ }^{1}$ Embrapa Solos, Rua Jardim Botânico, 1024 - 22460-000 - Rio de Janeiro - RJ \\ E-mail: thomaz@cnpms.embrapa.br; \{efidalgo, naime, zaroni\}@enps.embrapa.br \\ ${ }^{2}$ Geólogo. Petróleo Brasileiro S.A. - Petrobras. Av. Chile 65 - 20035-900 - Rio de Janeiro - RJ \\ E-mail: saulo.pedrinha@petrobras.com.br \\ ${ }^{3}$ Embrapa Agrobiologia, Rodovia BR 465, km 7 - 23890-000 - Seropédica - RJ \\ E-mail: mariella@cnpab.embrapa.br
}

\section{RESUMO}

Sub-bacias delimitadas para o estado do Rio de Janeiro foram parametrizadas por meio de duas metodologias que indicam vulnerabilidade, a equação universal de perda de solo que estima a perda de solo em toneladas por hectare/ano; e a integração temática de parâmetros morfométricos, topográficos, hidrológicos e de uso/cobertura da terra, que resulta em um índice de vulnerabilidade adimensional. Os parâmetros de cada método e os resultados foram analisados e comparados para verificação do grau de associação entre as metodologias, concluindo-se que os métodos são complementares para indicar vulnerabilidade de sub-bacia.

Palavras-chave: perda de solo; vulnerabilidade ambiental; sub-bacia.

\section{Vulnerability of the watersheds by universal equation of soil loss and thematic integration of morphometric, topographical, hydrological an land use/land cover parameters in Rio de Janeiro State, Brazil}

\begin{abstract}
Watersheds delimited in the Rio de Janeiro State were parameterized by means of two methods indicate that a measure of environmental vulnerability, the universal equation of soil loss, which estimates the loss of soil in tones per hectare per year, and thematic integration of morphometric, topographical, hydrological an land use/land cover parameters, that result at vulnerability index. The parameters involved and the results were compared to verify the degree of association between methodologies, concluding that these methods are complementary to indicate the vulnerability of watersheds.
\end{abstract}

Keywords: soil loss; environment vulnerability; watershed. 
COSTA, T. C. C.; FIDAlGO, E. C. C.; NAIME, U. J.; GUIMARÃES, S. P.; ZARONI, M. J.; UZEDA, M. C. Vulnerabilidade de sub-bacias hidrográficas por meio da equação universal de perda de solo e da integração de parâmetros morfométricos, topográficos, hidrológicos e de uso/cobertura da terra no estado do Rio de Janeiro, Brasil. Ambi-Agua, Taubaté, v. 4, n. 1, p. 93-116, 2009. (doi:10.4136/ambi-agua.76)

\section{INTRODUÇÃO}

Sub-bacias são compartimentos indicados para o gerenciamento ambiental, possibilitando o monitoramento hidrológico, a conservação do solo e a disciplina do uso da terra para produção de água em qualidade e quantidade, proteção da biodiversidade e produção sustentável.

A vulnerabilidade do solo à erosão pode ser indicada por parâmetros físicos e químicos, processos biológicos e antropogênicos. Os parâmetros antropogênicos, como a conversão da cobertura vegetal em outros usos, são responsáveis por expressivas alterações do ambiente natural e mudanças na paisagem, provocadas pela erosão do solo, o assoreamento e a contaminação dos recursos - água e solo, a redução na biodiversidade, dentre outros.

Para quantificar a perda de solo por erosão laminar, modelos, como a equação empírica USLE (Universal Soil Loss Equation) (Wischmeier e Smith, 1978), e o WEPP (Water Erosion Prediction Project), estimam perda de solo, sendo o WEPP mais completo, estimando também a deposição e taxa de arraste de sedimentos em sulcos (Flanagan e Nearing, 1995), mas exigindo um grande número de parâmetros de entrada (Bacchi et al., 2000).

A especificidade desses modelos, desenvolvidos experimentalmente, mostra que são apropriados para aplicação em escalas maiores, como uma gleba de terra ou uma microbacia, não em larga escala, quando existe conectividade entre feições, como bacias a montante e a jusante, ou quando a erosão de uma área pode contribuir com o assoreamento de outras áreas. A bacia hidrográfica com seus parâmetros morfométricos e de fluxo hídrico, pode ser então um método complementar na indicação da vulnerabilidade de terras (Costa et al., 2007).

Para os parâmetros obtidos por bacias hidrográficas, com pertinência à vulnerabilidade das terras, ainda não existem modelos empíricos comprovados, não sendo possível estabelecer relações estatísticas e funções, mesmo porque o índice de vulnerabilidade não é uma variável de mensuração definida, como a perda de solo em uma parcela. Uma forma é recorrer à integração temática por meio de um modelo de suporte à decisão. Um modelo usual e simples é a analise multicriterial (AMC), que executa a agregação de critérios, com a combinação linear de pesos, WLC (Eastman et al., 1995), para gerar variáveis objetivos, como índices de vulnerabilidade (Mendes e Motizuki, 2001; Fuller et al., 2002; Costa et al., 2003).

Essa técnica permite integrar uma complexidade de fatores de diferentes naturezas e escalas, atendendo a um ou múltiplos objetivos, embora forneça resultados com menor consistência e de difícil validação, comparado a um modelo empírico. Sua estratégia é o equilíbrio entre máxima descompensação entre fatores e o máximo risco (Eastman et al., 1995).

A USLE correlaciona a perda de solo com a capacidade erosiva de chuvas intensas, com a erodibilidade do solo, com a declividade contínua do terreno (rampa), com o grau de proteção da cobertura/uso da terra e com o nível de conservação do solo, exigindo o levantamento do perfil de solos, análise mineralógica e de infiltração para o cálculo da erodibilidade. As práticas de conservação de solo devem ser levantadas para cada gleba, e o grau de proteção da classe de uso/cobertura da terra tem que ser obtido, motivo pelo qual torna geralmente inviável sua aplicação em grandes extensões, para avaliar o grau de vulnerabilidade das terras. Por outro lado, parâmetros de bacias hidrográficas são relativamente fáceis de obter por meio de dados de sensoriamento remoto e técnicas de geoprocessamento, devendo-se investigar relações de pertinência entre a vulnerabilidade e parâmetros de bacias.

Parâmetros morfométricos, topográficos, hidrológicos e de uso/cobertura da terra, extraídos por bacias, tem alguma similaridade com os parâmetros da USLE, sendo alguns 
COSTA, T. C. C.; FIDALGO, E. C. C.; NAIME, U. J.; GUIMARÃES, S. P.; ZARONI, M. J.; UZEDA, M. C. Vulnerabilidade de sub-bacias hidrográficas por meio da equação universal de perda de solo e da integração de parâmetros morfométricos, topográficos, hidrológicos e de uso/cobertura da terra no estado do Rio de Janeiro, Brasil. Ambi-Agua, Taubaté, v. 4, n. 1, p. 93-116, 2009. (doi:10.4136/ambi-agua.76)

complementares. A forma da bacia e o escoamento superficial (runoff), por exemplo, não são considerados na equação universal, devido à sua abordagem pontual. Por outro lado, a fragilidade do solo não é considerada na parametrização de sub-bacias, que exigiria os mesmos levantamentos requeridos pela USLE.

O objetivo deste trabalho foi comparar a equação universal de perda de solo com uma metodologia que estabelece uma medida adimensional de vulnerabilidade em sub-bacias, por meio da integração temática de parâmetros morfométricos, topográficos, hidrológicos e de uso/cobertura da terra.

\section{MATERIAL E MÉTODOS}

A área experimental utilizada foi o estado do Rio de Janeiro, com ampla variação do meio físico, representado por sete unidades geomorfológicas (IBGE, 1983), que vão das planícies costeiras, entremeadas por colinas e maciços costeiros, e tabuleiros costeiros. Em direção ao interior, estão a Serra do Mar, o vale do rio Paraíba do Sul e pequenas porções da Serra da Mantiqueira. Fenômenos orográficos e de continentalidade conferem grandes amplitudes pluviométricas, assim como as variações edáficas e topográficas definem regiões distintas em uma pequena porção do território, garantindo variabilidade para o estudo proposto.

Para a delimitação das sub-bacias e a extração de variáveis morfométricas e topográficas, foi utilizado o modelo digital de elevação (MDE) da Missão de Lançamento de Radar Topográfico (SRTM) pela NASA (2005), resolução 90 x 90m, compatível com a escala 1:100.000 (Santos et al. 2005). Para corrigir o modelo, foram realizadas operações de interpolação de falhas, atenuação de ruídos e ajuste de depressões. As pequenas falhas foram interpoladas pela média de pixels vizinhos. As regiões com grandes falhas foram interpoladas separadamente, usando o método de kriging, por meio do software de modelagem geoestatística - GSTAT (Pebesma, 1998).

A atenuação de ruídos foi realizada com a transformação de Fourier, reconstituindo-se uma imagem corrigida ou melhorada, com um procedimento de filtragem no domínio das freqüências (Jensen, 1996, Figueiredo, 1977, Eastman, 2003). A finalidade dessa transformação foi suavizar feições para aumentar a eficiência e precisão na detecção automática, testando-se a aderência com sub-bacias delimitadas manualmente. O ajuste de depressões, que impedem a continuidade do fluxo hídrico, foi executado identificando pixels com cotas mais baixas, que têm variação de cota maior que o limiar estabelecido em relação a sua vizinhança, para serem uniformizados para a cota mais baixa da vizinhança, permitindo a continuidade do fluxo.

A delimitação de sub-bacias foi gerada automaticamente pelo método proposto por Janson e Domingue (1988), com o modelo MDE/SRTM corrigido, e foi editada com o apoio de 100 Cartas Topográficas da Divisão do Serviço Geográfico do Exército (DSG) e do IBGE na escala 1:50.000 que recobrem o Estado.

Baseando-se em uma revisão sobre variáveis morfométricas (Collares, 2000; Teixeira e Cruz, 2005; Ribeiro e Salomão, 2003; Milani e Canali, 2000; Rocha, 1991), foram selecionados parâmetros morfométricos e topográficos das sub-bacias, adequados para a escala de trabalho.

O parâmetro morfométrico densidade de drenagem é dado pela fórmula $D D=\frac{C D}{A}$, sendo $\mathrm{CD}=$ comprimento de drenagem, dado por $C D=\sum R+\sum C+\sum T$, sendo $\mathrm{R}=$ ravinas; $\mathrm{C}=$ canais; e $\mathrm{T}=$ tributários, em km; e $\mathrm{A}=$ área da sub-bacia, em hectare (ha). 
COSTA, T. C. C.; FIDAlGO, E. C. C.; NAIME, U. J.; GUIMARÃES, S. P.; ZARONI, M. J.; UZEDA, M. C. Vulnerabilidade de sub-bacias hidrográficas por meio da equação universal de perda de solo e da integração de parâmetros morfométricos, topográficos, hidrológicos e de uso/cobertura da terra no estado do Rio de Janeiro, Brasil. Ambi-Agua, Taubaté, v. 4, n. 1, p. 93-116, 2009. (doi:10.4136/ambi-agua.76)

Para a detecção da drenagem a partir do modelo digital de elevação, o escoamento superficial foi reclassificado a partir de testes com limiares, verificando-se a superposição da drenagem gerada com composições coloridas Landsat e o layer de drenagem das cartas topográficas. As linhas de drenagem obtidas dessa forma representam ravinas, canais e tributários não restituídos nas cartas topográficas do levantamento sistemático do DSG e do IBGE.

Para estimar o comprimento da drenagem na estrutura raster, formada por segmentos contínuos de pixels de 90 x $90 \mathrm{~m}$, executou-se o seguinte procedimento: um segmento é um conjunto de direções vertical, horizontal, ou diagonal, em que cada pixel participa com um comprimento de 90 metros (se a direção for vertical ou horizontal), ou com um comprimento de 127,279 metros, se a direção for diagonal. Dessa forma, estima-se o comprimento de drenagem como: $C D=n$ pixels $(2 \times 90 \mathrm{~m}+1 \times 127,279 \mathrm{~m}) / 3=n$ pixels $\times 102,426 \mathrm{~m}$.

Para validação da densidade de drenagem estimada, os valores foram comparados com os de 13 microbacias da sub-bacia do rio Soturno, obtidos em levantamento de campo por Rocha (1991).

O parâmetro morfométrico índice de circularidade, é calculado pela expressão $\mathrm{IC}=\mathrm{A} / \mathrm{AC}$, sendo $\mathrm{A}=$ área da bacia (ha) e $\mathrm{AC}=$ área do círculo de perímetro igual ao da bacia considerada $\left(\mathrm{AC}=\mathrm{P}^{2} / 4 \pi\right)$.

O parâmetro declividade percentual média da bacia (DECL) foi calculado do modelo digital de elevação pelo gradiente médio entre células vizinhas, pelo módulo Slope do Idrisi (Eastman, 2003), usando a fórmula:

$$
D E C L=\sqrt{\left(\frac{A l t_{\text {dir }}-A l t_{\text {esq }}}{180}\right)^{2}+\left(\frac{A l t_{\text {sup }}-A l t_{\text {inf }}}{180}\right)^{2}} * 100
$$

O desvio padrão da altitude (DPALT) é um parâmetro complementar à declividade média, mensurando a dispersão da altitude. Bacias com maior dispersão em altitude apresentam maior velocidade hídrica, devido às maiores amplitudes topográficas e, portanto, maior capacidade de arraste do solo, sendo mais vulneráveis.

O parâmetro hidrológico, escoamento superficial (RUNOFF), indica a situação de cada pixel em relação à captação pluvial e recepção de água de áreas vizinhas, incluindo a de bacias a montante, na direção do fluxo hídrico. O parâmetro indicador da magnitude do escoamento superficial para uma sub-bacia é o seu valor máximo, conforme o exemplo dado na Figura 1.

Na comparação entre a média, total e valor máximo, a média atenua a intensidade real de escoamento na bacia, enquanto o parâmetro total o superestima, porque acumula $o$ escoamento. O parâmetro que informa o escoamento superficial total da chuva na bacia é ovalor máximo do pixel que se encontra na foz. Por causa da conexão entre bacias a montante e a jusante, esse valor não é somente a quantidade de chuva precipitada na bacia, mas indica bacias com maior recepção na drenagem, considerando bacias a montante. Esse parâmetro foi calculado pelo módulo RUNOFF do Idrisi, utilizando-se a precipitação anual em $\mathrm{mm}$, 
COSTA, T. C. C.; FIDALGO, E. C. C.; NAIME, U. J.; GUIMARÃES, S. P.; ZARONI, M. J.; UZEDA, M. C. Vulnerabilidade de sub-bacias hidrográficas por meio da equação universal de perda de solo e da integração de parâmetros morfométricos, topográficos, hidrológicos e de uso/cobertura da terra no estado do Rio de Janeiro, Brasil. Ambi-Agua, Taubaté, v. 4, n. 1, p. 93-116, 2009. (doi:10.4136/ambi-agua.76)

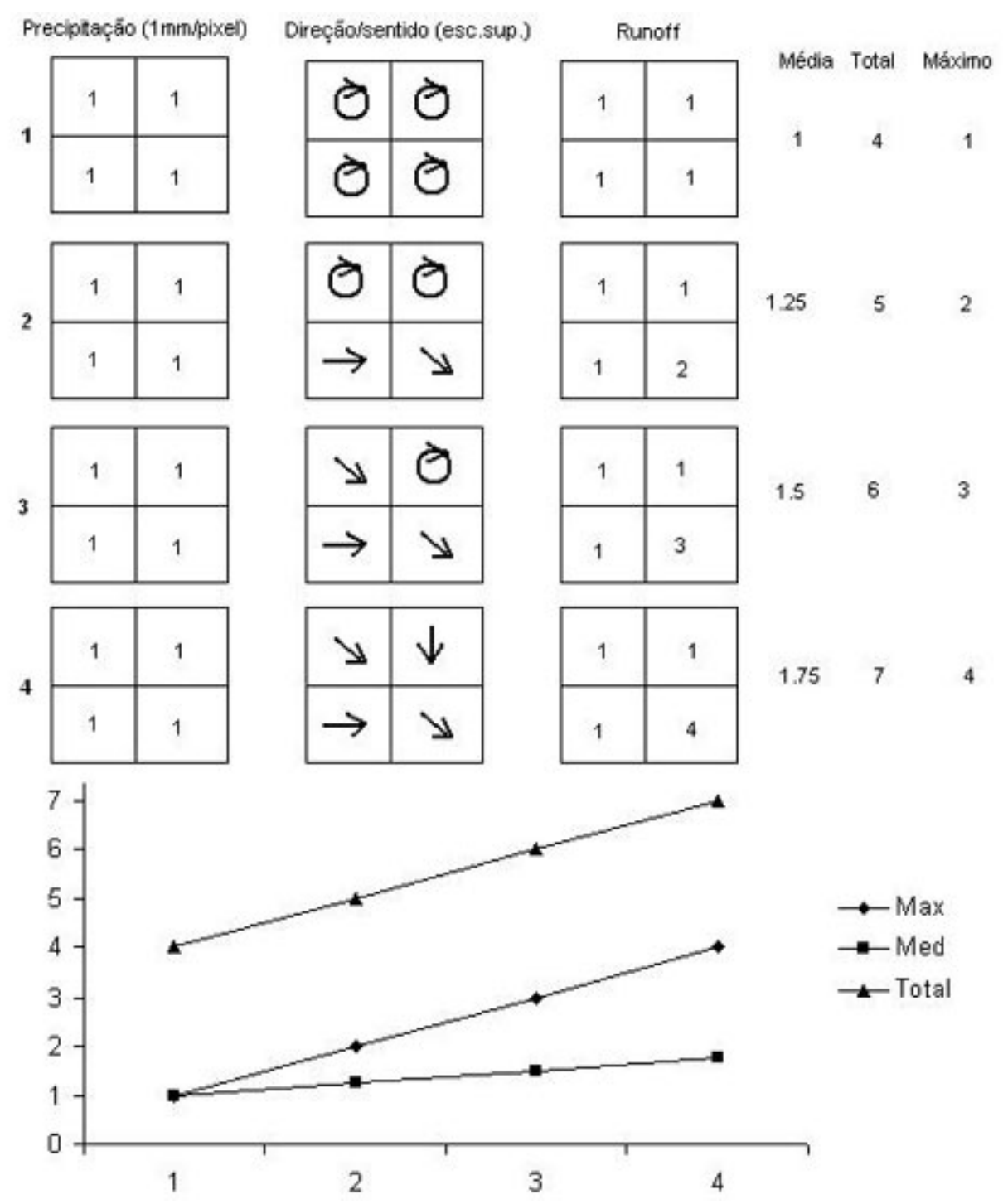

Figura 1. Escoamento superficial para uma área de captação de quatro pixels, variando da condição completamente plana para o máximo escoamento superficial, com recepção de $1 \mathrm{~mm}$ de chuva por pixel.

espacializada pela interpolação por kriging, no software de modelagem geoestatística-GSTAT (Pebesma, 1998), com os dados da série histórica de 1973 a 2000, de 18 estações pertencentes ao Instituto Nacional de Meteorologia (INMET) e 59 estações pluviométricas da Agência Nacional de Águas (2005) (Alfonsi et al., 2003). Parâmetros de infiltração de água no solo não foram considerados, significando que toda a água precipitada irá escorrer.

Os parâmetros de uso/cobertura da terra referem-se às classes de maior ocorrência no mapeamento e correspondem às proporções de área na sub-bacia. Foram consideradas: área relativa da cobertura florestal dada pela área de fragmentos/área da sub-bacia (COBVEG) do mapeamento de remanescentes da Mata Atlântica (Fundação SOS Mata Atlântica, 2002), na escala 1:50.000; e áreas relativas de agricultura (AGRIC), pastagem (PAST) e área urbana (URBAN), extraídas do mapeamento do uso/cobertura da terra (Fundação Centro de Informações e Dados do Rio de Janeiro, 2000).

A correlação entre os parâmetros foi avaliada, tendo como critério a agregação de parâmetros com alto grau de correlação. 
COSTA, T. C. C.; FIDAlGO, E. C. C.; NAIME, U. J.; GUIMARÃES, S. P.; ZARONI, M. J.; UZEDA, M. C. Vulnerabilidade de sub-bacias hidrográficas por meio da equação universal de perda de solo e da integração de parâmetros morfométricos, topográficos, hidrológicos e de uso/cobertura da terra no estado do Rio de Janeiro, Brasil. Ambi-Agua, Taubaté, v. 4, n. 1, p. 93-116, 2009. (doi:10.4136/ambi-agua.76)

\subsection{Vulnerabilidade de sub-bacia hidrográfica}

$\mathrm{O}$ índice de vulnerabilidade de sub-bacias foi calculado por meio da agregação entre $\mathrm{n}$ parâmetros $\left(\mathrm{x}_{\mathrm{i}}\right)$, pela média aritmética, em que a variável objetivo (S) é o índice de vulnerabilidade: $\mathrm{S}=\Sigma \mathrm{x}_{\mathrm{i}} / \mathrm{n}$. Esse critério foi adotado pelo desconhecimento especialista para arbitrar diferentes graus de importância entre os fatores, não sendo necessário aplicar a AHP (Analytical Hierarchy Process), técnica de atribuição de pesos extrínsecos $\left(\mathrm{w}_{\mathrm{i}}\right)$ aos fatores (Eastman, 2003).

Por causa das diferentes escalas em que cada fator é mensurado, esses foram normalizados para uma escala continua (1byte) que se estende do valor de menor vulnerabilidade (0) para o valor de maior vulnerabilidade (255). A transformação de valores foi linear, que segue a relação de pertinência de cada fator, sendo a proporção de cobertura vegetal, o único fator com relação inversa à vulnerabilidade de bacias.

\subsection{Equação Universal de Perda de Solo}

A USLE é uma equação empírica não linear que estima perda de solo (A), em $\mathrm{Mg} / \mathrm{ha}$.ano, por meio dos fatores $\mathrm{R}=$ erosividade da chuva (MJ.mm/ha.h.ano), $\mathrm{K}=$ erodibilidade do solo (Mg.h/MJ.mm), L = comprimento de rampa (m), $\mathrm{S}=$ declividade (classes em graus), $\mathrm{C}=$ uso e manejo (magnitude da contribuição), e $\mathrm{P}=$ práticas conservacionistas (magnitude da mitigação): $\mathrm{A}=\mathrm{R}$ x K x L x S x C x P.

$\mathrm{O}$ fator $\mathrm{R}$, uma medida da intensidade da energia cinética da chuva, foi estimado pela soma dos valores mensais do índice de erosividade, em MJ.mm/ha.h.mês obtidos pela equação $\mathrm{Rm} \approx \mathrm{EI}_{30} \approx 89,823\left(\mathrm{r}^{2} / \mathrm{P}\right)^{0,759}$, recomendada por Lombardi para as condições do Estado do Rio de Janeiro, em Carvalho Júnior (1985). Essa equação é uma aproximação do produto da energia cinética da chuva (E) pela sua intensidade máxima em 30 min $\left(\mathrm{I}_{30}\right)$. Foram utilizados os dados de precipitação mensal (r) e anual (P), em mm, da série histórica de 1973 a 2000, e a espacialização da erosividade foi gerada pela interpolação por kriging no software GSTAT.

A erodibilidade é determinada pelas características físicas, químicas e morfológicas do solo. Para estimar o fator K, tomou-se como base o mapa de solo do estado do Rio de Janeiro publicado em Carvalho Filho et al. (2003a; 2003b), na escala 1:250.000. A definição do fator $\mathrm{K}$ para as 161 unidades de mapeamento de solo para o estado do Rio de Janeiro, sendo 458 classes distribuídas em quatro níveis categóricos, foi realizada por meio de levantamento bibliográfico de valores de $\mathrm{K}$ para classes ocorrentes ou similares às presentes no estado do Rio de Janeiro (Bertoni e Lombardi Neto 1985; Galdino et al., 2003; Longhi e Meneses, 2005; Moreira Sá et al., 2004; Pimenta 2005a; Silva, 2004; Vasquez-Fernandez et al., 1996). Esses valores foram sistematizados e outlyers foram eliminados.

A etapa seguinte foi o enquadramento em graus de erodibilidade das classes de solo, com sua posterior conversão para valores de $\mathrm{K}$ padronizados (Tabela 1). Como exemplo, pesquisados os valores de $\mathrm{K}=0,008,0,028$ e 0,033 para a classe Argissolo Vermelho Eutrófico, o valor 0,008 foi eliminado e a classe obteve o grau de moderado a forte, recebendo o K padronizado de 0,030 .

A próxima etapa correspondeu ao cálculo do fator $\mathrm{K}$ para as 161 unidades de mapeamento pedológico, considerando as diferentes proporções de ocorrência das classes de solo, identificadas até o $4^{\circ}$ nível categórico, ou seja, para cada unidade podem existir até quatro classes de solos, de forma que as proporções de ocorrências dessas classes estão discriminadas. Assim, em cada unidade de mapeamento, executa-se uma ponderação entre os fatores $\mathrm{K}$ de cada classe de solo por sua proporção na unidade, obtendo-se a média ponderada para cada unidade de mapeamento (Tabela 2). 
COSTA, T. C. C.; FIDAlgO, E. C. C.; NAIME, U. J.; GUIMARÃES, S. P.; ZARONI, M. J.; UZEDA, M. C. Vulnerabilidade de sub-bacias hidrográficas por meio da equação universal de perda de solo e da integração de parâmetros morfométricos, topográficos, hidrológicos e de uso/cobertura da terra no estado do Rio de Janeiro, Brasil. Ambi-Agua, Taubaté, v. 4, n. 1, p. 93-116, 2009. (doi:10.4136/ambi-agua.76)

Tabela 1. Graus de Limitação devidos à erodibilidade.

\begin{tabular}{cc}
\hline Graus de Limitação & Fator $\mathbf{K}:$ erodibilidade $\mathbf{~ M g . h / M J . m m ) ~}$ \\
\hline 0: nulo & $\mathrm{K}<=0,010$ \\
1: ligeiro & $0,010<=\mathrm{K}<0,020$ \\
2: moderado & $0,020<=\mathrm{K}<0,030$ \\
3: forte & $0,030<=\mathrm{K}<0,040$ \\
4: muito forte & $\mathrm{K}>=0,040$ \\
\hline
\end{tabular}

Fonte: Adaptado de Giboshi (1999).

A próxima etapa correspondeu ao cálculo do fator $\mathrm{K}$ para as 161 unidades de mapeamento pedológico, considerando as diferentes proporções de ocorrência das classes de solo, identificadas até o $4^{\circ}$ nível categórico, ou seja, para cada unidade podem existir até quatro classes de solos, de forma que as proporções de ocorrências dessas classes estão discriminadas. Assim, em cada unidade de mapeamento, executa-se uma ponderação entre os fatores $\mathrm{K}$ de cada classe de solo por sua proporção na unidade, obtendo-se a média ponderada para cada unidade de mapeamento (Tabela 2).

Tabela 2. Média ponderada de K para a unidade de mapeamento PAx3.

\begin{tabular}{l|lcc}
\hline Unidade & \multicolumn{1}{|c}{ Classes de solo } & Proporção (\%) & Fator K \\
\hline \multirow{4}{*}{ PAx3 } & Argissolo Amarelo coeso & 40 & 0,030 \\
& Argissolo Amarelo distrófico & 30 & 0,025 \\
& Argissolo Vermelho-Amarelo distrófico & 30 & 0,025 \\
& & & \\
\cline { 2 - 4 } & Total & $\mathbf{1 0 0}$ & $\mathbf{0 , 0 2 7}$ \\
\hline
\end{tabular}

O fator LS foi obtido pelo módulo da equação de perda de solo revisada (RUSLE) do Idrisi Kilimanjaro, utilizando-se o MDE/SRTM. O valor do comprimento de rampa é dado por: $\mathrm{L}=(\lambda / 22,13)^{\mathrm{m}}$, sendo 22,13 , o comprimento da parcela experimental em metros (Wishmeier e Smith, 1978); $\lambda$ = projeção horizontal do comprimento de rampa; e $\mathrm{m}=$ variável comprimento-declividade, definido pela expressão (Renard et al., 1997): $m=\beta /(1+\beta)$, onde $\beta$ é a razão da erosão em sulcos, causada pelo fluxo da água, pela erosão na região entre sulcos, causada principalmente pelo impacto da chuva.

Em solos onde a susceptibilidade à erosão em sulcos e entre sucos é moderada, $\beta$ é dado pela fórmula (McCool et al., 1989, in: Eastman, 2003): $\beta=(\operatorname{sen} \theta / 0,0896) /[3 \times(\operatorname{sen} \theta) 0,8+$ $0,56]$, sendo $\theta$ a declividade.

Um fator de ajuste para $\beta$ é aplicado conforme limiares estabelecidos para o fator $C$, do uso e cobertura do solo: se o solo for exposto $(\mathrm{C}=1), \beta$ será multiplicado por 2 ; se a cobertura no solo for do tipo $(\mathrm{C})<=0,004, \beta$ será dividido por 2 .

O cálculo do fator $\mathrm{S}$ (steepness, classes de declive, ou declividade máxima na direção da rampa), é dado pelas expressões (McCool et al., 1987, in: Eastman, 2003) conforme o limiar de declividade: $S=10,8 \times \operatorname{sen} \theta+0,03$ para $\theta<9 \%$; ou $S=16,8 \times \operatorname{sen} \theta-0,50$ para $\theta>=9 \%$.

$\mathrm{O}$ fator $\mathrm{C}$, parâmetro de proteção do solo para cada classe de uso da terra, foi definido por meio de pesquisa bibliográfica (Bertoni e Lombardi Neto, 1985; Brito et al., 1998; Paranhas Filho et al., 2003; Bueno e Stein, 2004; Santos et al., 2005; Galdino, 2003; Moreira Sá et al., 2004; Pimenta, 2005b), considerando valores médios de classes similares ou iguais 
COSTA, T. C. C.; FIDAlGO, E. C. C.; NAIME, U. J.; GUIMARÃES, S. P.; ZARONI, M. J.; UZEDA, M. C. Vulnerabilidade de sub-bacias hidrográficas por meio da equação universal de perda de solo e da integração de parâmetros morfométricos, topográficos, hidrológicos e de uso/cobertura da terra no estado do Rio de Janeiro, Brasil. Ambi-Agua, Taubaté, v. 4, n. 1, p. 93-116, 2009. (doi:10.4136/ambi-agua.76)

às ocorrentes no estado do Rio de Janeiro, do Mapa de Uso e Cobertura do Solo (Fundação Centro de Informações e Dados do Rio de Janeiro, 2000).

$\mathrm{O}$ fator $\mathrm{P}$ foi uniformemente definido como 1 (valor máximo), que indica a não existência de práticas conservacionistas, ou seja, a condição crítica no processo de erosão.

A perda de solo obtida por pixel foi convertida para a perda de solo média por sub-bacia hidrográfica, possibilitando a comparação entre os dois métodos pelo coeficiente de correlação de postos de Spearman (Siegel, 1956), devido à natureza não paramétrica de alguns dados.

\section{RESULTADOS E DISCUSSÃO}

\subsection{Vulnerabilidade de sub-bacia hidrográfica}

Os resultados de densidade de drenagem por sub-bacias em $\mathrm{km} / \mathrm{ha}$ (DD) foram comparados com os levantamentos detalhados em microbacias, em que os pontos em vermelho correspondem a DD e DECL de 13 microbacias da sub-bacia do Rio Soturno (Rocha, 1991) (Figura 2). Os dados de densidade de drenagem processados do MDE apresentam variação com amplitude similar aos dados de campo, sendo uma prova de consistência do método utilizado.

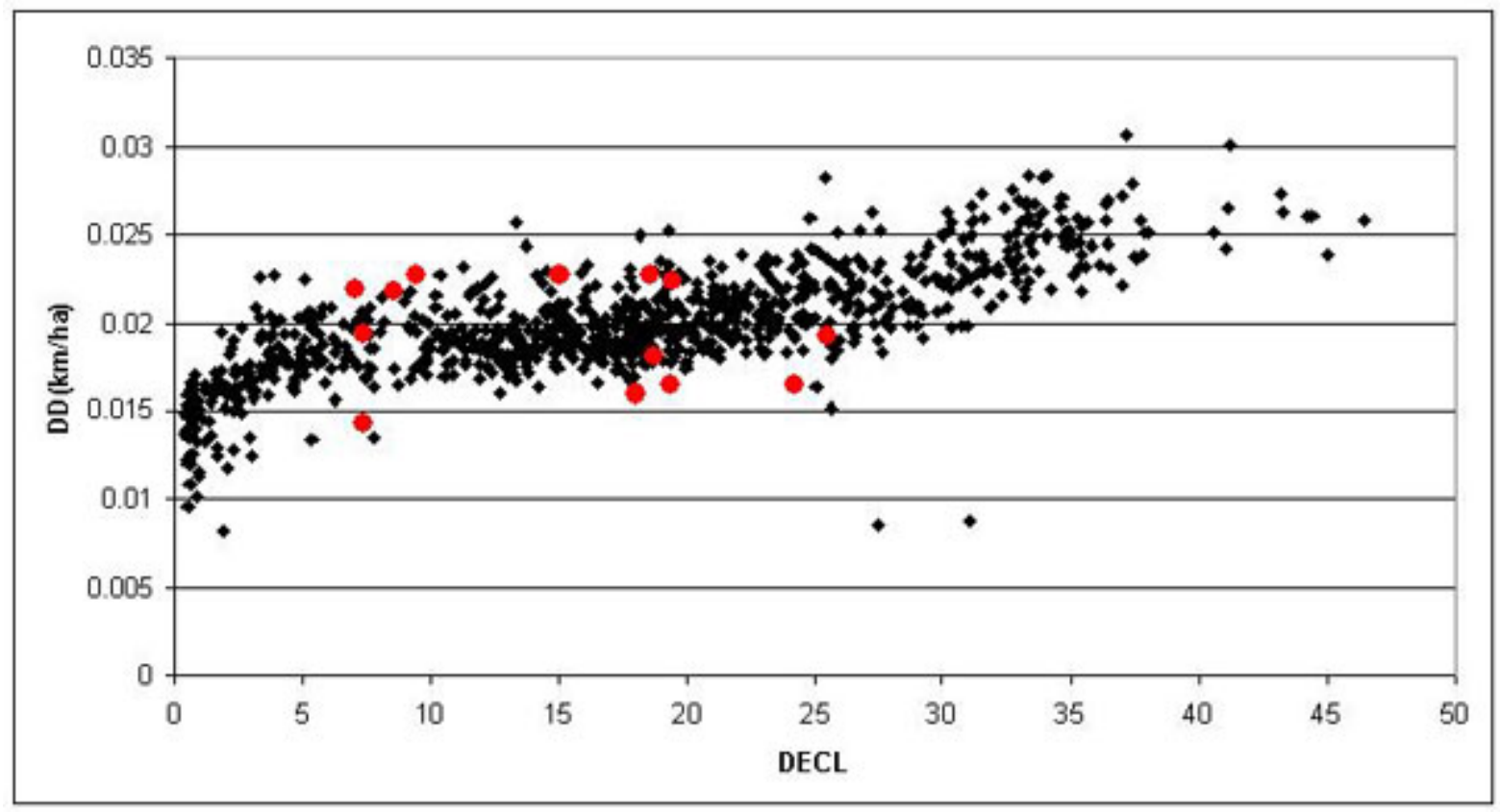

Figura 2. Dispersão da Densidade de Drenagem (DD em km/ha) em função da declividade média percentual de sub-bacias hidrográficas (DECL). Pontos em vermelho, Fonte: DD e DECL de 13 microbacias da sub-bacia do Rio Soturno (Rocha, 1991).

A densidade de drenagem é um indicador da eficiência natural ao escoamento superficial de água e se relaciona com o risco de ocorrência de cheias, processos erosivos e permeabilidade (transmissibilidade) do terreno. Bacias hidrográficas com altas densidades de drenagem apresentam baixas transmissibilidades (impermeáveis), ao contrário de bacias com baixas densidades de drenagem (permeáveis).

Foi constatada uma densidade de drenagem alta, entre 0,025 e $0,031 \mathrm{~km} / \mathrm{ha}$, nas Unidades dos Maciços Costeiros, Escarpas Serranas (Serra do Mar - Planalto da Bocaína e Serra dos Órgãos) e Mantiqueira Meridional - Planalto de Itatiaia (Figura 3). 
COSTA, T. C. C.; FIDAlgO, E. C. C.; NAIME, U. J.; GUIMARÃES, S. P.; ZARONI, M. J.; UZEDA, M. C. Vulnerabilidade de sub-bacias hidrográficas por meio da equação universal de perda de solo e da integração de parâmetros morfométricos, topográficos, hidrológicos e de uso/cobertura da terra no estado do Rio de Janeiro, Brasil. Ambi-Agua, Taubaté, v. 4, n. 1, p. 93-116, 2009. (doi:10.4136/ambi-agua.76)

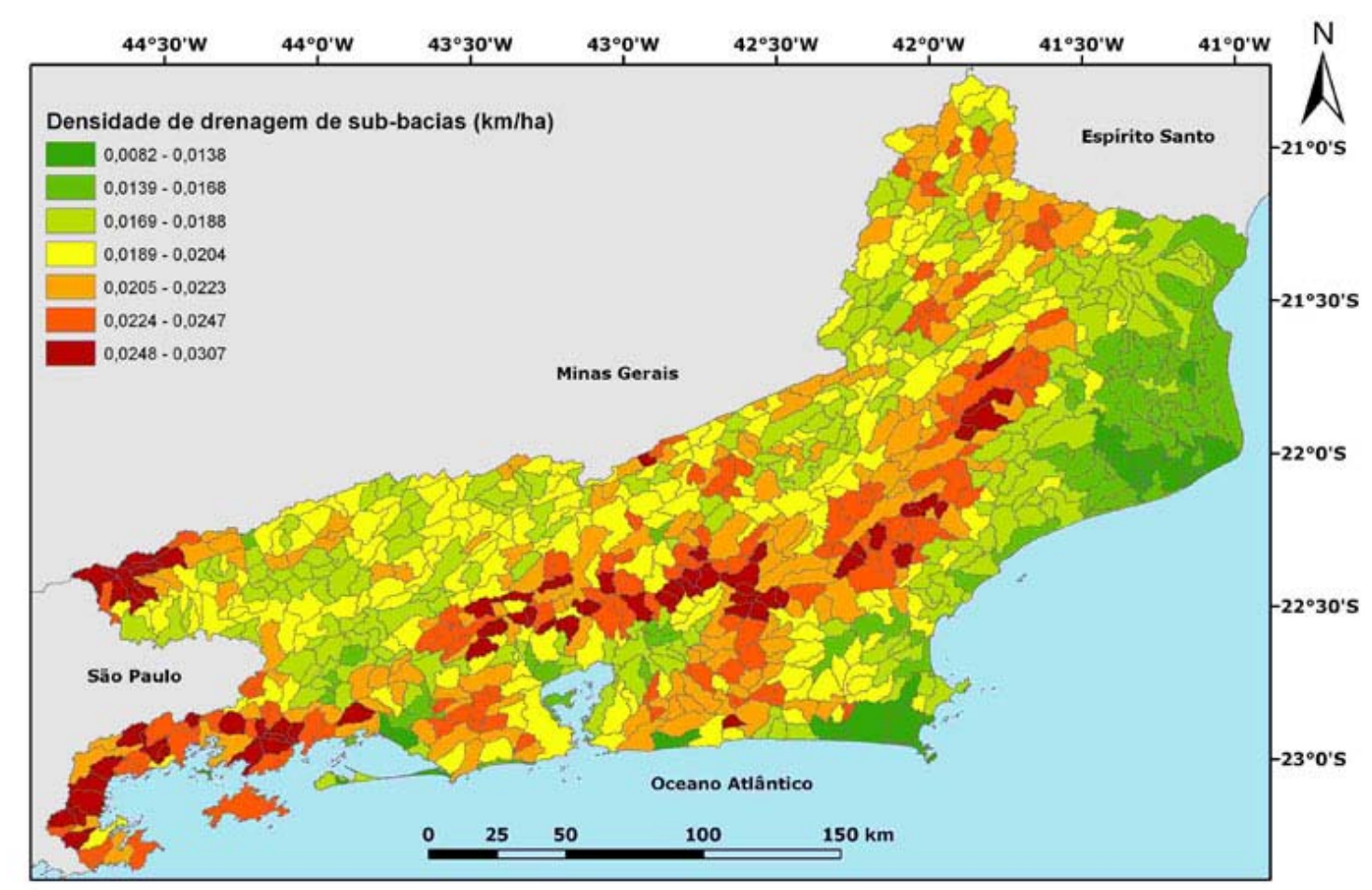

Figura 3. Densidade de drenagem (km/ha) para sub-bacias do estado do Rio de Janeiro.

Densidades intermediárias ocorrem nas depressões e nos alinhamentos de cristas do Paraíba do Sul, incluindo compartimentos planálticos do Leste de Minas, no Noroeste Fluminense e nas Colinas e Maciços Costeiros próximos ao litoral. Regiões com densidade de drenagem baixa são encontradas na baixada litorânea ao leste do Estado, nas Unidades Planícies Costeiras e Tabuleiros de Bacias Sedimentares, onde ocorre predominância de terrenos sedimentares, em que raramente aflora o substrato rochoso. Isso faz com que a transmissibilidade do terreno seja alta, diminuindo a densidade de drenagem nessas regiões. Essas unidades apresentam um baixo potencial de vulnerabilidade aos processos erosivos e movimentos de massa devido à baixa declividade.

Sub-bacias com maior desvio padrão da altitude na bacia (Figura 4) encontram-se protegidas por Unidades de Conservação (UC), como o Parque Nacional de Itatitaia e a APA da Serra da Mantiqueira, Parque Nacional dos Três Picos, Parque Nacional da Serra dos Órgãos, Reserva Biológica do Tinguá, Parque Nacional da Serra da Bocaina e Parque Estadual do Desengano. Essas áreas mantiveram os grandes remanescentes da Mata Atlântica, posteriormente protegidos pelo poder público.

O parâmetro de forma, índice de circularidade, mede a proximidade da forma da bacia ao círculo. Quanto mais próxima da forma circular $(\approx 1)$, maiores os riscos de erosão, assoreamento e enchente na bacia. Esse risco está relacionado com a velocidade e sincronia de tempo entre os escoamentos da água de chuva provenientes das cabeceiras dos rios.

Numa bacia de forma próxima da circular, os escoamentos convergem em instantes similares para pontos próximos, aumentando rapidamente o deflúvio acumulado para o canal principal da bacia, potencializando a carga hídrica, os processos erosivos, o assoreamento e com maior risco de enchentes. Em uma bacia alongada, o deflúvio ocorre em pontos distantes e com um tempo diferente para esses escoamentos chegarem ao mesmo ponto do canal principal, resultando em menor vazão.

O índice de circularidade (Figura 5) indicou uma fraca associação entre o formato da bacia e a geomorfologia e com a densidade de drenagem, declividade e variação da altitude na 
COSTA, T. C. C.; FIDAlGO, E. C. C.; NAIME, U. J.; GUIMARÃES, S. P.; ZARONI, M. J.; UZEDA, M. C. Vulnerabilidade de sub-bacias hidrográficas por meio da equação universal de perda de solo e da integração de parâmetros morfométricos, topográficos, hidrológicos e de uso/cobertura da terra no estado do Rio de Janeiro, Brasil. Ambi-Agua, Taubaté, v. 4, n. 1, p. 93-116, 2009. (doi:10.4136/ambi-agua.76)

bacia (Tabela 3). A distribuição heterogênea do formato de bacias é observada em quase todas as formações, com exceção do norte fluminense, com depósitos sedimentares (planícies e tabuleiros), onde predomina a forma alongada.

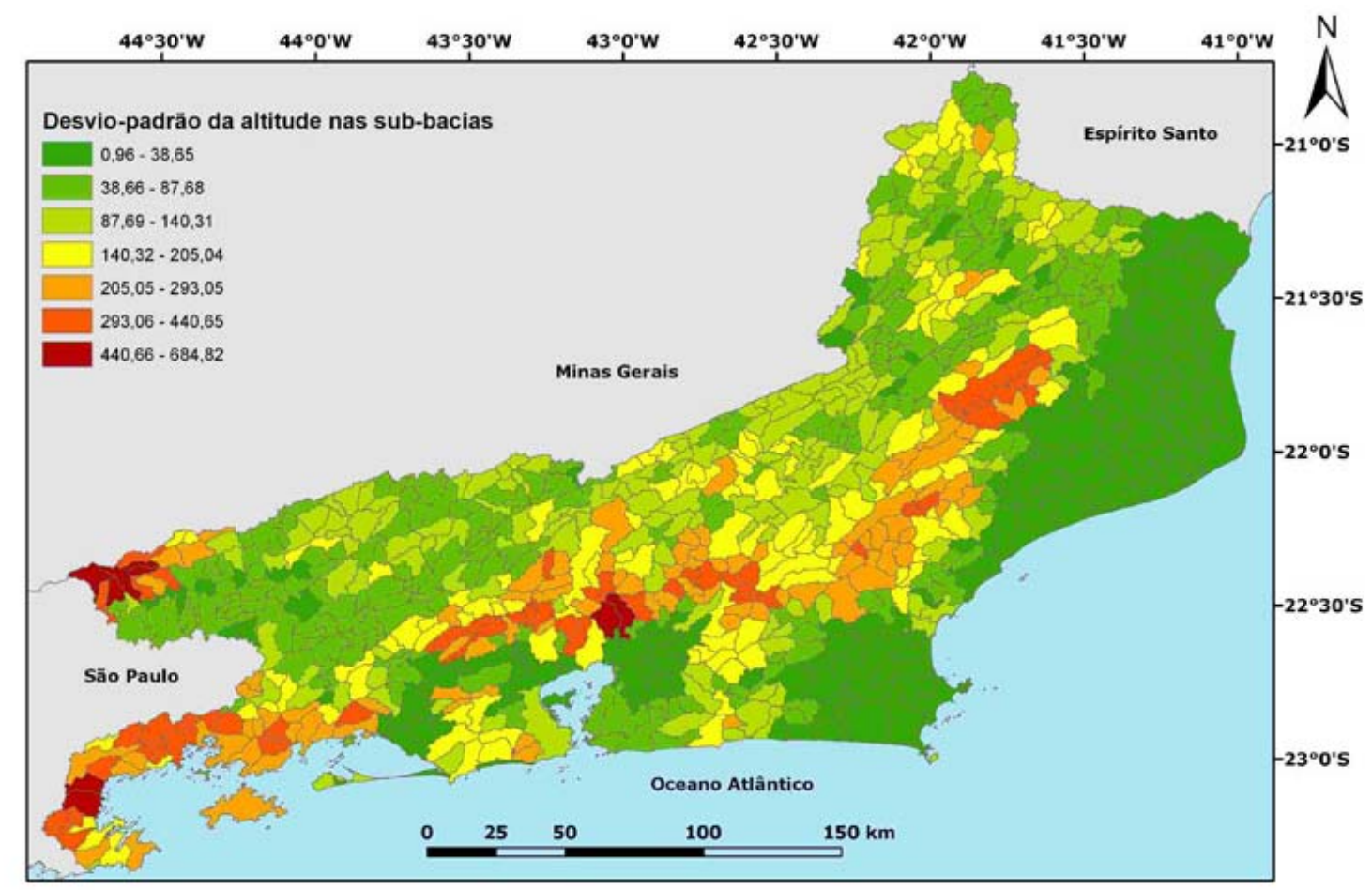

Figura 4. Desvio-padrão da altitude para sub-bacias do estado do Rio de Janeiro.

Tabela 3. Correlação de Spearman $>30(\mathrm{p}<0,000000, \mathrm{n}=883)$ entre parâmetros indicadores de vulnerabilidade de bacias hidrográficas.

\begin{tabular}{lccc}
\hline & Spearma & $\mathbf{t}(\mathbf{N}-2)$ & $\mathbf{p}$ \\
\hline DD e IC & 0,346115 & 10,9501 & 0,000000 \\
DD e DECL & 0,753299 & 33,9971 & 0,000000 \\
DD e DPALT & 0,831386 & 44,4072 & 0,000000 \\
DD e COBVEG & 0,485925 & 16,5023 & 0,000000 \\
IC e DECL & 0,313745 & 9,8077 & 0,000000 \\
DECL e DPALT & 0,902276 & 62,1142 & 0,000000 \\
DECL e COBVEG & 0,611666 & 22,9489 & 0,000000 \\
DECL e AGRIC & $-0,408066$ & $-13,2669$ & 0,000000 \\
DPALT e COBVEG & 0,673887 & 27,0724 & 0,000000 \\
DPALT e AGRIC & $-0,348089$ & $-11,0211$ & 0,000000 \\
COBVEG e PAST & $-0,351752$ & $-11,1533$ & 0,000000 \\
AGRIC e PAST & $-0,325082$ & $-10,2031$ & 0,000000 \\
\hline
\end{tabular}


COSTA, T. C. C.; FIDAlgO, E. C. C.; NAIME, U. J.; GUIMARÃES, S. P.; ZARONI, M. J.; UZEDA, M. C. Vulnerabilidade de sub-bacias hidrográficas por meio da equação universal de perda de solo e da integração de parâmetros morfométricos, topográficos, hidrológicos e de uso/cobertura da terra no estado do Rio de Janeiro, Brasil. Ambi-Agua, Taubaté, v. 4, n. 1, p. 93-116, 2009. (doi:10.4136/ambi-agua.76)

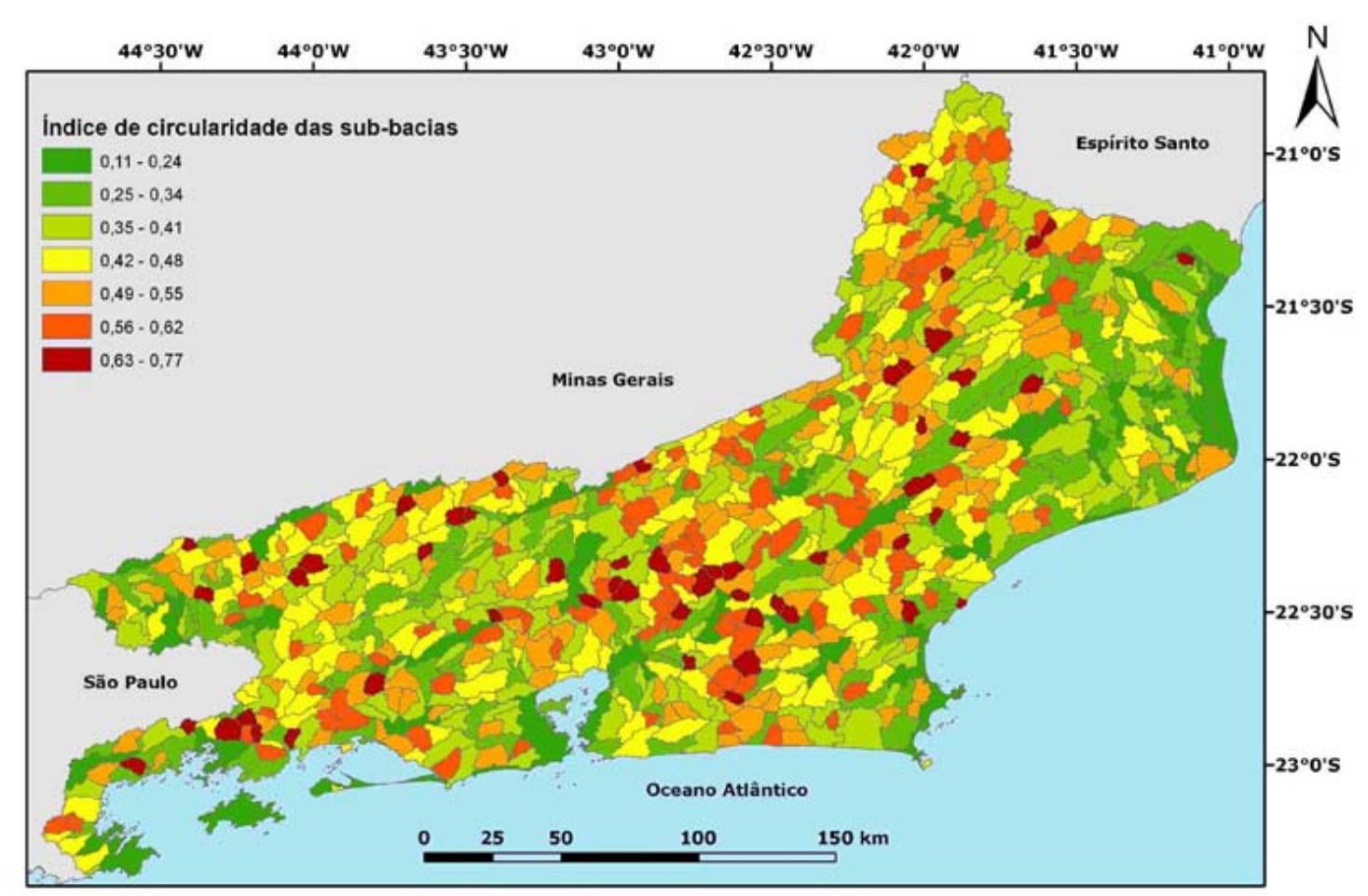

Figura 5. Índice de Circularidade para sub-bacias do estado do Rio de Janeiro.

O parâmetro RUNOFF é não correlacionado com outros parâmetros. A maior magnitude de escoamento superficial ocorre na região dos grandes rios, na lagoa de Araruama, no Norte Fluminense, em direção à Lagoa Feia, e para o oceano, na bacia de Campos (Figura 6). Nessa mesma região, ocorre uma concentração de sedimentos na faixa litorânea em direção ao alto mar, identificada em imagens de satélite Landsat. A moderada magnitude de escoamento superficial ocorre nos cordões arenosos, no delta do Paraíba do Sul, na saída para o manguezal de Guapimirim, que serve como um dissipador de energia, depositando sedimentos antes de atingir a baía de Guanabara. Outra região é a da baía de Sepetiba, onde se observam alguns sedimentos.

Verifica-se que o escoamento superficial é complementar às variáveis topográficas em processos erosivos, pois indica as regiões de maior deflúvio e potencial de arraste pela carga hídrica. Na Tabela 3 acima, são apresentadas as principais correlações significativas entre os parâmetros analisados. Densidade de drenagem, declividade percentual e desvio padrão da altitude na bacia são parâmetros com alta correlação entre si. A dispersão entre DECL e DPALT, que obteve a maior correlação $(>0,90)$ é visualizada na Figura 7.

Em análise de regressão, variáveis explicativas correlacionadas entre si causam instabilidades nos estimadores, devido à correlação serial. Em técnicas de agregação de dados temáticos, variáveis correlacionadas repetem a contribuição de atributos similares para o objetivo. Dessa forma, optou-se pelo produto entre as três variáveis, resultando na variável conjunta DDxDECLxDPALT.

Verificou-se que sub-bacias com maior densidade de drenagem $(>\mathrm{DD})$, geralmente têm maior declividade média (>DECL) e variação de altitude (>DPALT). Essas condições compensam a maior propensão a processos erosivos, pelo acesso difícil às atividades antrópicas (<AGRIC, <PAST), favorecendo a manutenção da vegetação (>COBVEG). A ausência da cobertura vegetal é um fator de grande peso na vulnerabilidade de sub-bacias, principalmente em áreas críticas, como as de preservação permanente, definidas pelo Código Florestal (Brasil, 1965). 
COSTA, T. C. C.; FIDAlGO, E. C. C.; NAIME, U. J.; GUIMARÃES, S. P.; ZARONI, M. J.; UZEDA, M. C. Vulnerabilidade de sub-bacias hidrográficas por meio da equação universal de perda de solo e da integração de parâmetros morfométricos, topográficos, hidrológicos e de uso/cobertura da terra no estado do Rio de Janeiro, Brasil. Ambi-Agua, Taubaté, v. 4, n. 1, p. 93-116, 2009. (doi:10.4136/ambi-agua.76)

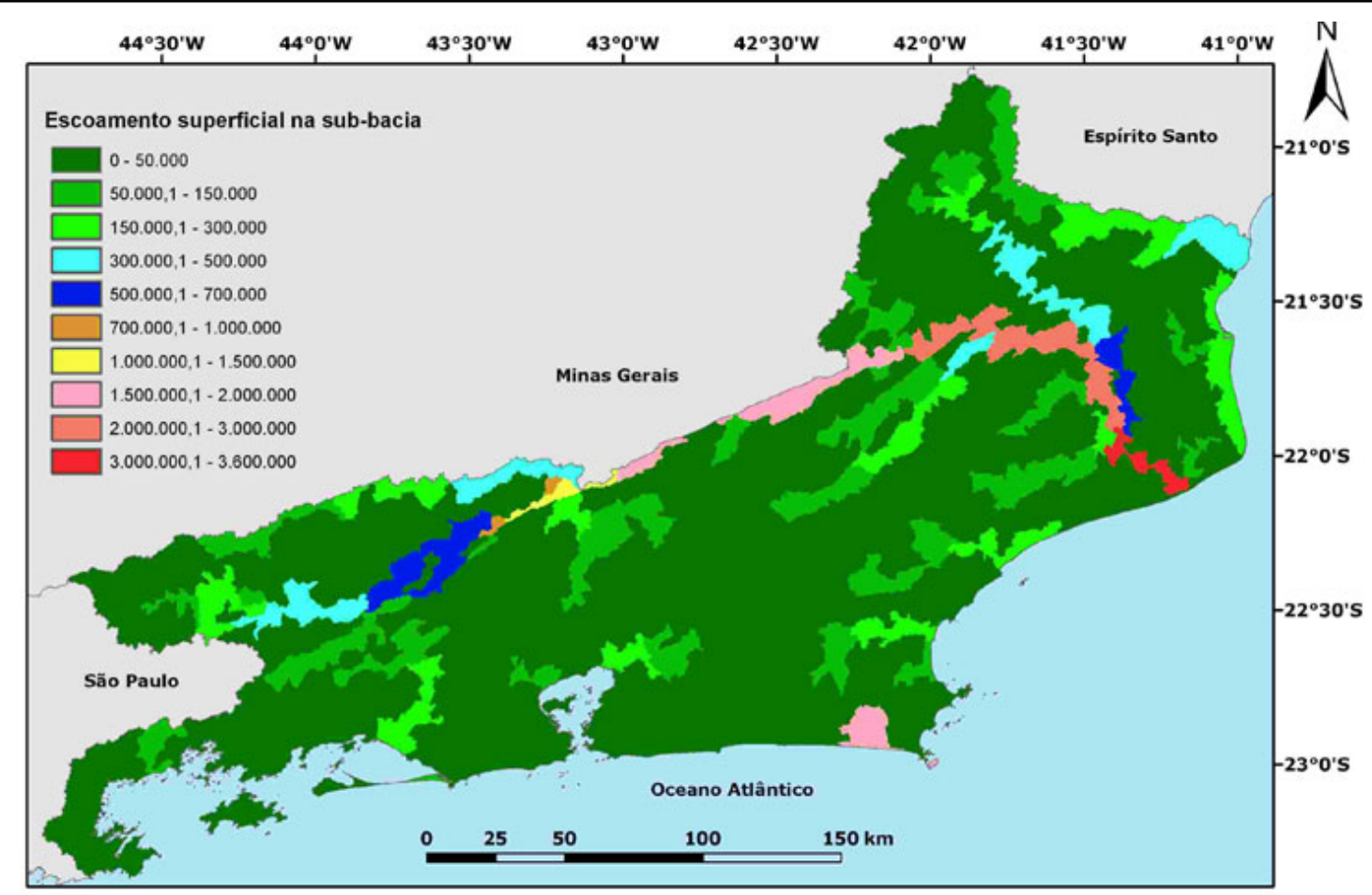

Figura 6. Escoamento superficial ( $\mathrm{mm} / \mathrm{pixel})$ na foz de sub-bacias do estado do Rio de Janeiro.

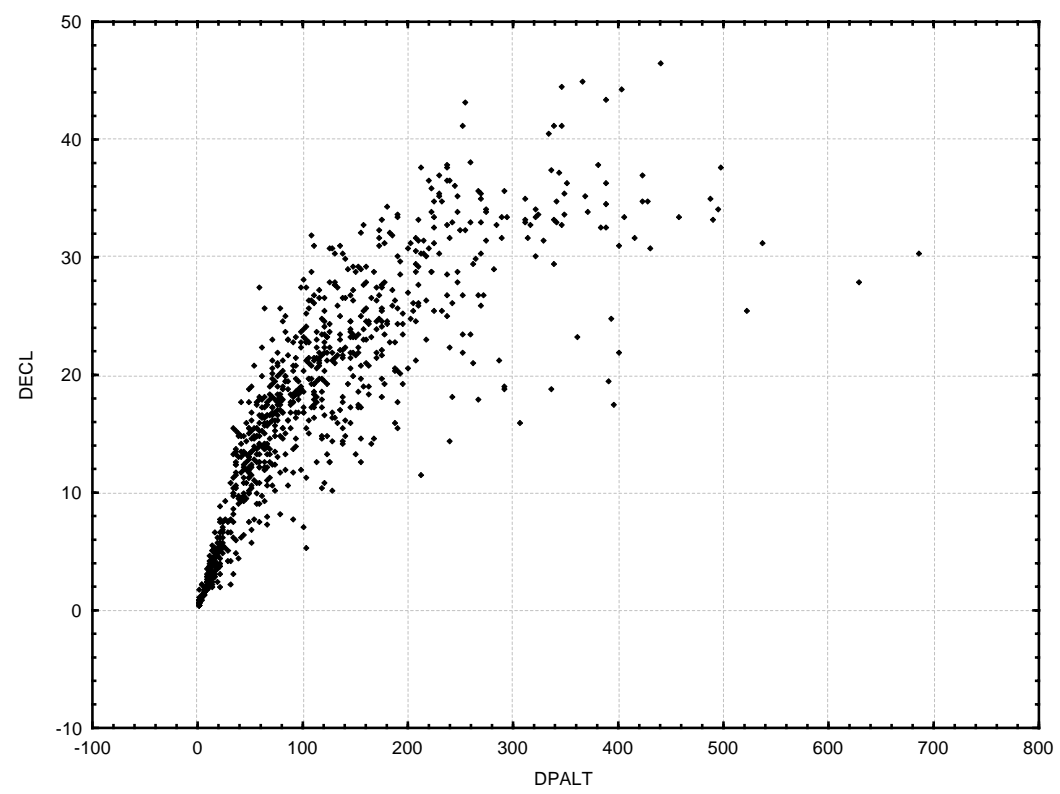

Figura 7. Dispersão da Declividade média percentual de sub-bacias hidrográficas (DECL), em função do desvio padrão da altitude (DPALT).

A agricultura (AGRIC) é um dos principais fatores de degradação, devido ao manejo inadequado que expõe o solo à erosão hídrica, afeta a estrutura e reduz a matéria orgânica. E as pastagens (PAST) constituem outro fator de vulnerabilidade, pois em manejos inadequados e em áreas inaptas são causas de compactação e perda da fertilidade do solo, resultando em processos erosivos, como ravinamentos, erosão laminar e voçorocamentos. E as áreas urbanas (URBAN) têm impactos potenciais em sub-bacias hidrográficas, exigindo ações corretivas 
COSTA, T. C. C.; FIDAlGO, E. C. C.; NAIME, U. J.; GUIMARÃES, S. P.; ZARONI, M. J.; UZEDA, M. C. Vulnerabilidade de sub-bacias hidrográficas por meio da equação universal de perda de solo e da integração de parâmetros morfométricos, topográficos, hidrológicos e de uso/cobertura da terra no estado do Rio de Janeiro, Brasil. Ambi-Agua, Taubaté, v. 4, n. 1, p. 93-116, 2009. (doi:10.4136/ambi-agua.76)

pontuais, com gestão ambiental distinta do escopo rural. A impermeabilização do solo (aumentando o risco de enchentes), a ocupação em áreas com risco de deslizamento e a disposição de resíduos urbanos e industriais são alguns dos problemas relacionados com a vulnerabilidade em bacias hidrográficas urbanas.

$\mathrm{Na}$ Figura 8, é apresentado o índice de vulnerabilidade de bacias hidrográficas pela integração dos parâmetros: DDxDECLxDPALT, IC, RUNOFF, COBVEG, AGRIC, PAST, URBAN. Verifica-se uma concentração de sub-bacias mais vulneráveis no noroeste, com histórico da degradação de pastagens, no oeste do vale do Paraíba, e na região norte.

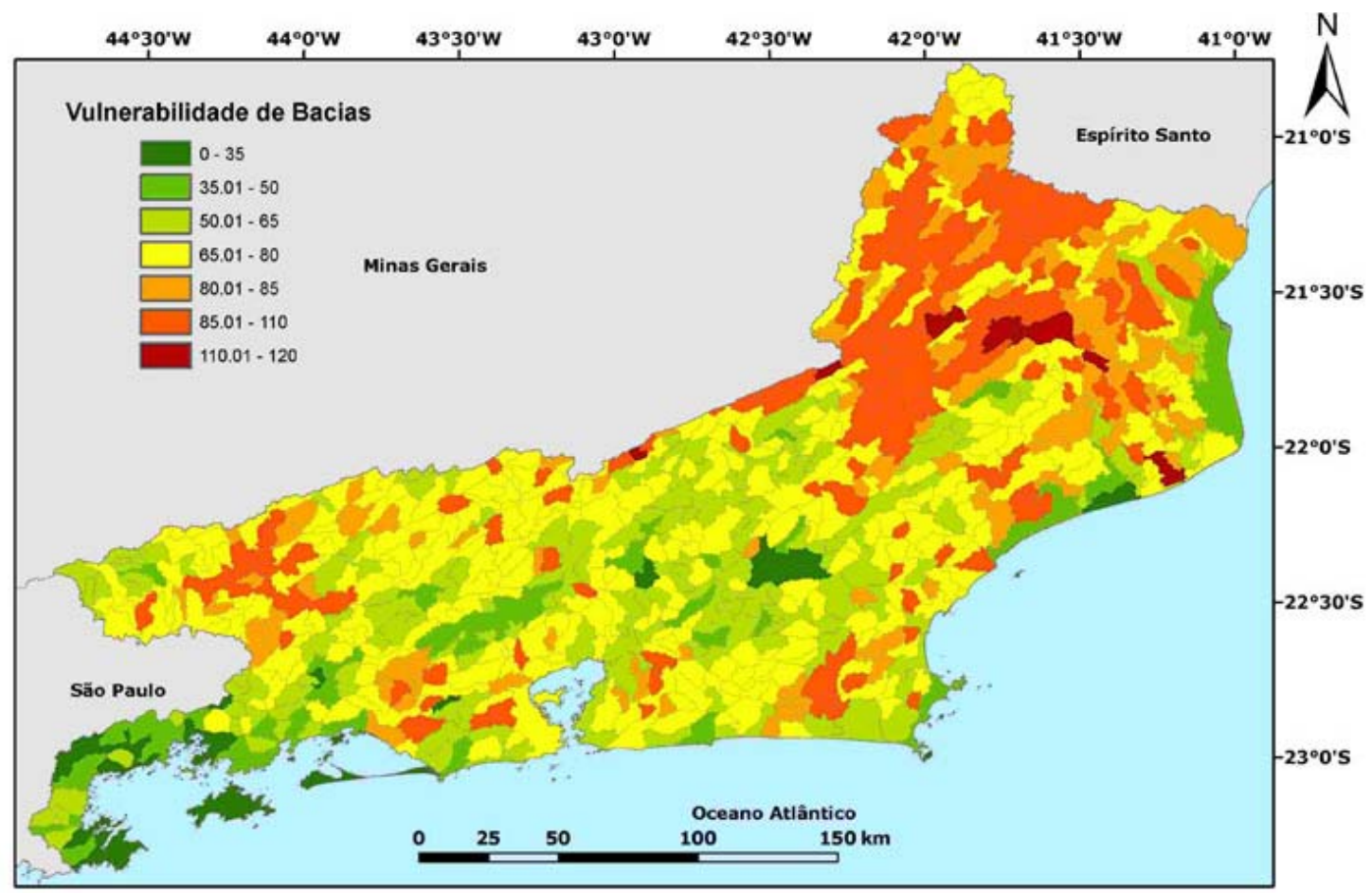

Figura 8. Índice de Vulnerabilidade de sub-bacias do estado do Rio de Janeiro.

\subsection{Equação Universal de Perda de Solo}

Considerando os parâmetros da USLE, o índice de erosividade (R) ficou entre 4000 e 11000MJ.mm/ha.h.ano, com os maiores valores, acima de 10.000MJ.mm/ha.h.ano, nas Serras do Mar e da Mantiqueira, e os menores valores no litoral norte fluminense, região dos Lagos e na parte leste da baía de Sepetiba (Figura 9).

As regiões com solos menos erodíveis (fator $\mathrm{K}$ ) concentram-se no norte fluminense, regiões alagadiças na baía de Sepetiba e manguezal de Guapimirim na baía de Guanabara, e as com solos mais erodíveis concentram-se na Serra do Mar, na região noroeste do estado do Rio de Janeiro e no leito do rio Paraíba do Sul na porção sul e centro do estado (Figura 10). 
COSTA, T. C. C.; FIDAlGO, E. C. C.; NAIME, U. J.; GUIMARÃES, S. P.; ZARONI, M. J.; UZEDA, M. C. Vulnerabilidade de sub-bacias hidrográficas por meio da equação universal de perda de solo e da integração de parâmetros morfométricos, topográficos, hidrológicos e de uso/cobertura da terra no estado do Rio de Janeiro, Brasil. Ambi-Agua, Taubaté, v. 4, n. 1, p. 93-116, 2009. (doi:10.4136/ambi-agua.76)

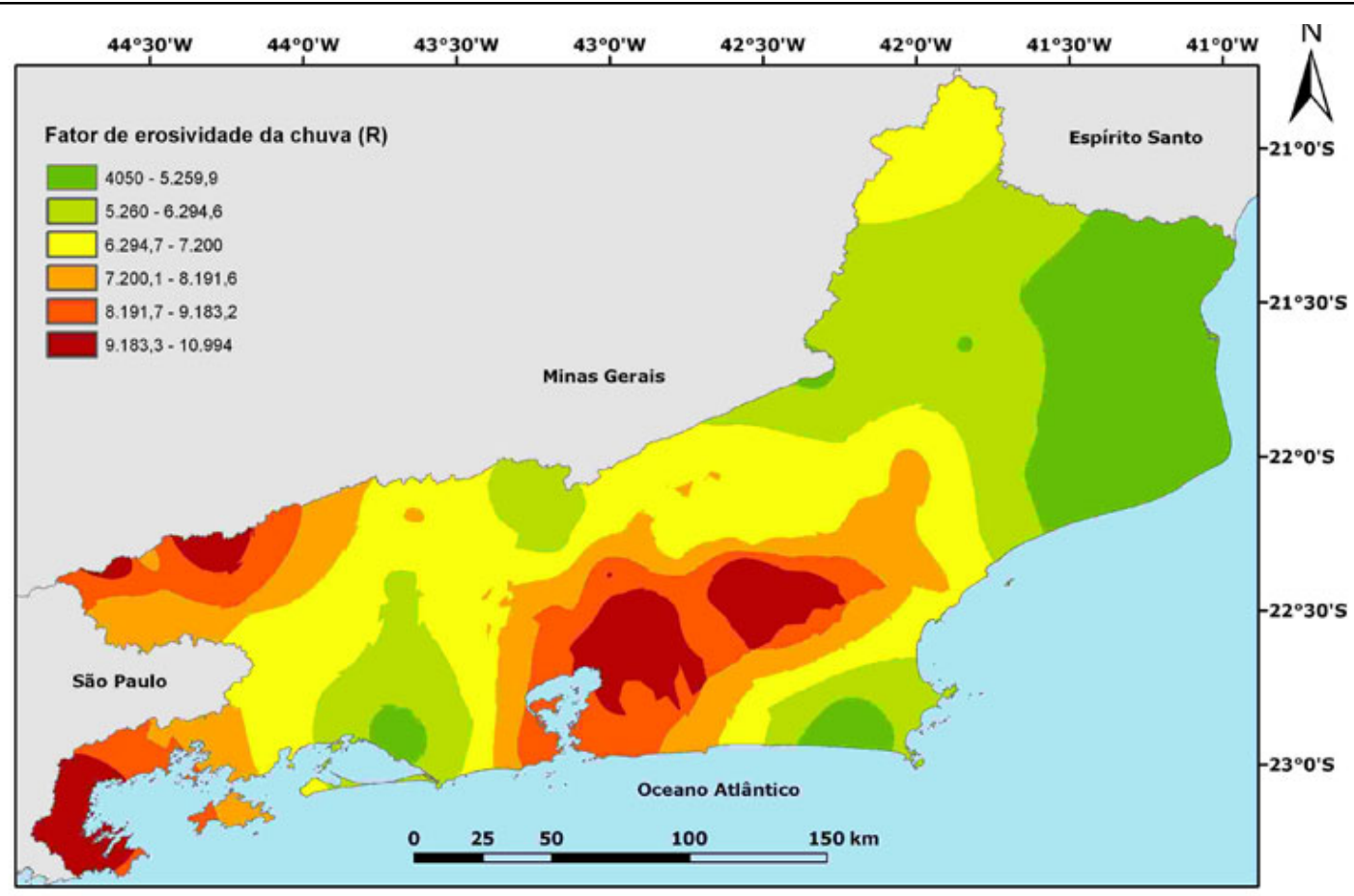

Figura 9. Índice de erosividade anual (R), EI em MJ.mm/ha.h.ano, para o estado do Rio de Janeiro.

Para o fator LS, observa-se alta correlação com o relevo, expressando seu maior valor nas feições escarpadas da Serra do Mar, da Mantiqueira e em maciços costeiros (Figura 11).

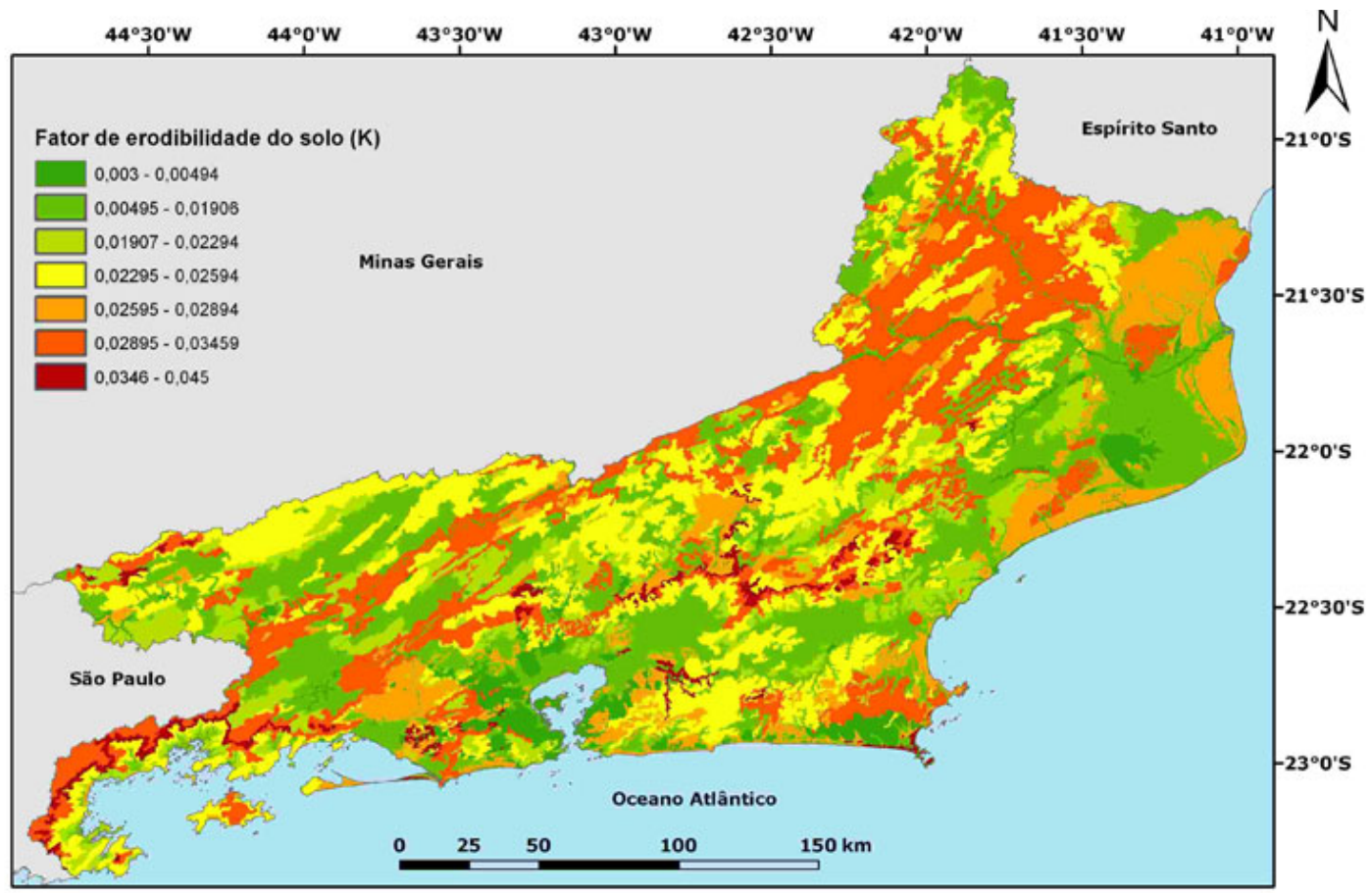

Figura 10. Erodibilidade do solo (fator K), em Mg.h/MJ.mm, para o estado do Rio de Janeiro. 
COSTA, T. C. C.; FIDAlgO, E. C. C.; NAIME, U. J.; GUIMARÃES, S. P.; ZARONI, M. J.; UZEDA, M. C. Vulnerabilidade de sub-bacias hidrográficas por meio da equação universal de perda de solo e da integração de parâmetros morfométricos, topográficos, hidrológicos e de uso/cobertura da terra no estado do Rio de Janeiro, Brasil. Ambi-Agua, Taubaté, v. 4, n. 1, p. 93-116, 2009. (doi:10.4136/ambi-agua.76)

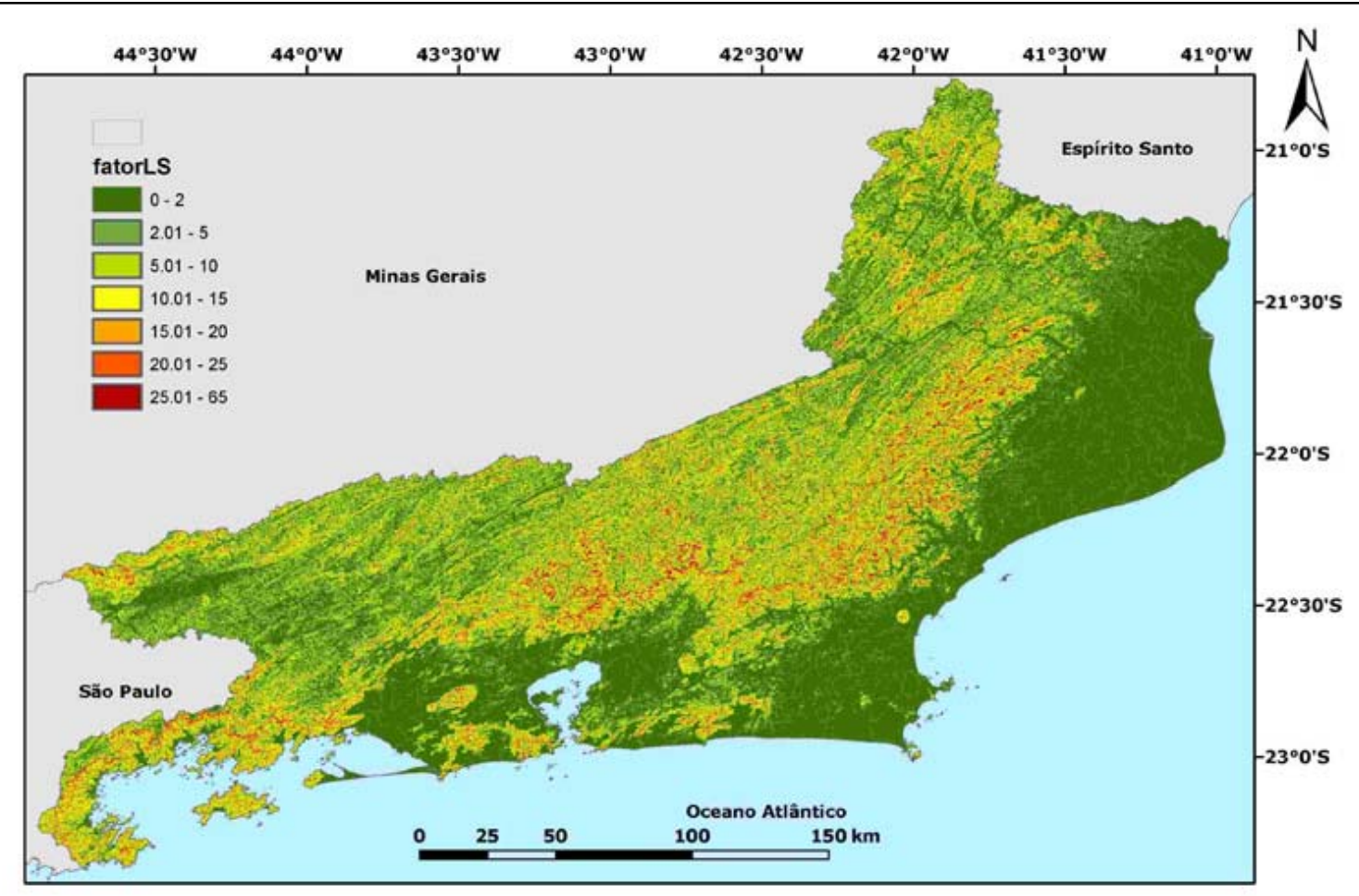

Figura 11. Fator LS para o estado do Rio de Janeiro.

$\mathrm{O}$ fator $\mathrm{C}$ foi atribuído para as classes do mapeamento de uso/cobertura da terra realizado pela Fundação CIDE, conforme apresentado na Tabela 4.

$\mathrm{Na}$ Figura 12 é apresentado o resultado da equação universal de perda de solo, obtendose a perda média de solo por sub-bacia (Mg/ha.ano). Paranhas Filho et al. (2003), com uma análise temporal de perdas de solo por erosão laminar para a bacia do rio Taquarizinho, no estado de Mato Grosso do Sul, obtiveram valores de perdas de 4,44 Mg/ha.ano em 1966; 5,53 $\mathrm{Mg} / \mathrm{ha}$.ano em 1985 e 8,65 Mg/ha.ano em 1996, estando a média abaixo de $15 \mathrm{Mg} / \mathrm{ha}$.ano, e raras ocorrências acima de $200 \mathrm{Mg} / \mathrm{ha}$.ano. Na bacia do Alto Taquari, no estado do Mato Grosso, ocorreram perdas médias da ordem de $70 \mathrm{Mg} / \mathrm{ha}$.ano, com 7,79\% da área com perdas acima de $200 \mathrm{Mg} /$ ha. ano (Galdino et al. 2003).

Observa-se que as sub-bacias com maiores estimativas de perdas de solo ocorrem no médio vale do rio Paraíba do Sul, no noroeste, na parte ocidental do norte fluminense e em contrafortes da Serra do Mar. Embora as regiões das Serras da Bocaína-Litoral Sul, Serra dos Órgãos e Serra da Mantiqueira apresentem solos de elevada erodibilidade e relevo muito acidentado, a perda de solos é atenuada devido à proteção aos processos erosivos pela elevada incidência de remanescentes florestais. A grande divergência entre os resultados da USLE e o índice de vulnerabilidade ocorre em regiões planas e de convergência de fluxos hídricos.

\subsection{Comparação entre os métodos}

$\mathrm{Na}$ Tabela 5, são apresentadas associações entre os parâmetros de cada método. Os parâmetros $\mathrm{R}$ e $\mathrm{K}$ são complementares ao método da vulnerabilidade de sub-bacias, pois o parâmetro erodibilidade do solo não é considerado, e a pluviosidade, acessória no cálculo do Runoff, não tem relação com capacidade erosiva, contribuindo apenas para a lâmina de água superficial. 
COSTA, T. C. C.; FIDAlGO, E. C. C.; NAIME, U. J.; GUIMARÃES, S. P.; ZARONI, M. J.; UZEDA, M. C. Vulnerabilidade de sub-bacias hidrográficas por meio da equação universal de perda de solo e da integração de parâmetros morfométricos, topográficos, hidrológicos e de uso/cobertura da terra no estado do Rio de Janeiro, Brasil. Ambi-Agua, Taubaté, v. 4, n. 1, p. 93-116, 2009. (doi:10.4136/ambi-agua.76)

Tabela 4. Valores para o fator $\mathrm{C}$ das classes de uso e cobertura do solo do mapeamento realizado pela Fundação Centro de Informações e Dados do Rio de Janeiro (2000).

\begin{tabular}{|c|c|c|}
\hline Código da Classe & Uso e Cobertura solo & Fator C \\
\hline 1 & Afloramento Rochoso & 0,0100000 \\
\hline 2 & Área agrícola & 0,2558821 \\
\hline 3 & Área inundável & 0,0050000 \\
\hline 4 & Área não classificada & 0,0578286 \\
\hline 5 & Área urbana (alta densidade) & 0,0050000 \\
\hline 6 & Área urbana (baixa densidade) & 0,0100000 \\
\hline 7 & Área urbana (média densidade) & 0,0075000 \\
\hline 8 & Área urbanizada & 0,0053333 \\
\hline 9 & Campo de altitude & 0,0194000 \\
\hline 10 & Campo-pastagem & 0,0288000 \\
\hline 11 & Encosta degradada & 0,0480000 \\
\hline 12 & Estepe arbórea & 0,0007000 \\
\hline 13 & Floresta estacional semidecidual & 0,0007000 \\
\hline 14 & Floresta ombrófila densa & 0,0001000 \\
\hline 15 & Grandes construções & 0,0100000 \\
\hline 16 & Mangue & 0,0050000 \\
\hline 17 & Mangue Degradado & 0,0050000 \\
\hline 20 & Praia & 0,0050000 \\
\hline 21 & Reflorestamento & 0,0085000 \\
\hline 22 & Rios, lagos e lagoas & 0,0000000 \\
\hline 23 & Salinas & 0,0050000 \\
\hline 24 & Solo exposto & 1,0000000 \\
\hline 25 & Vegetação de restinga & 0,0007000 \\
\hline 26 & Vegetação de várzea & 0,0100000 \\
\hline 27 & Vegetação secundária & 0,0001000 \\
\hline
\end{tabular}

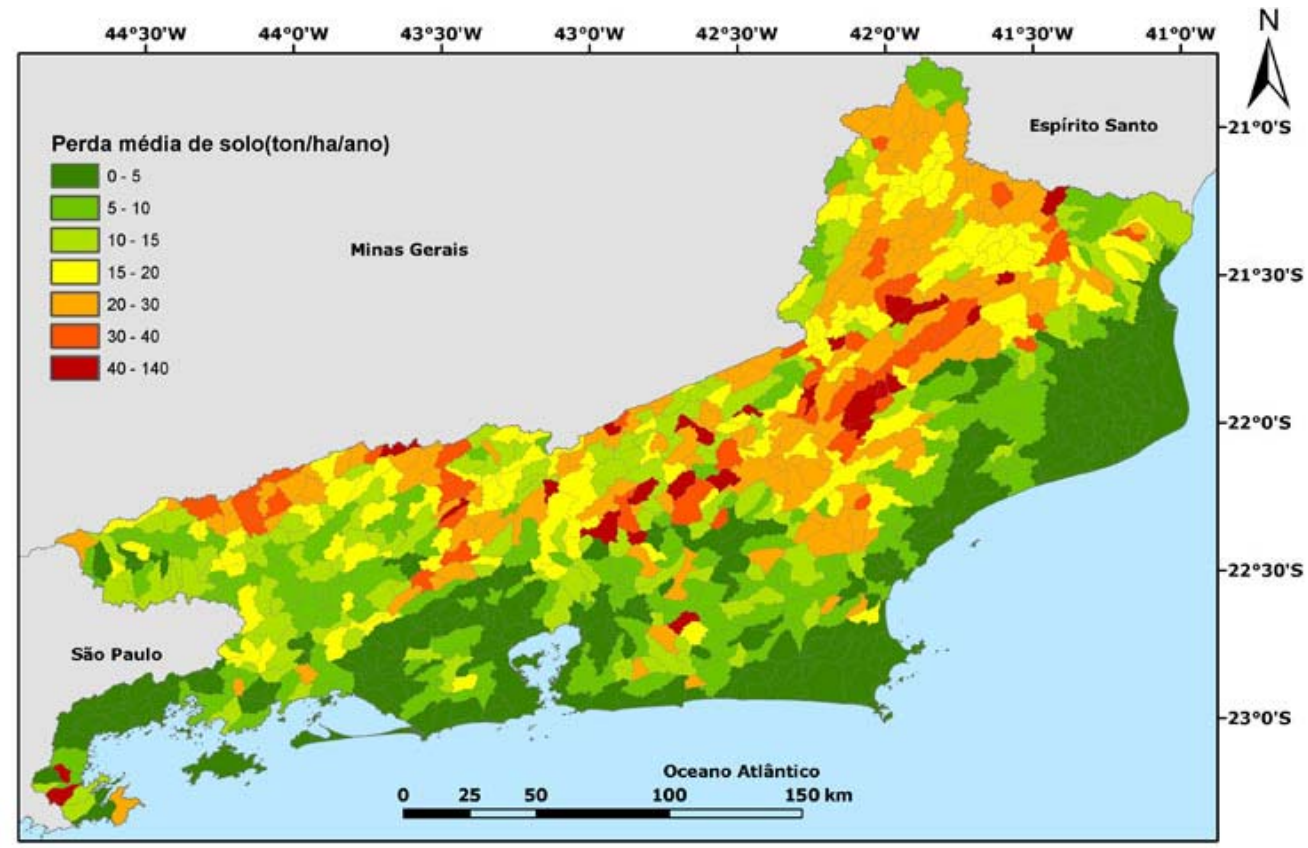

Figura 12. Perda média de solo para as sub-bacias do estado do Rio de Janeiro, em $\mathrm{Mg}$ /ha.ano. 
COSTA, T. C. C.; FIDAlGO, E. C. C.; NAIME, U. J.; GUIMARÃES, S. P.; ZARONI, M. J.; UZEDA, M. C. Vulnerabilidade de sub-bacias hidrográficas por meio da equação universal de perda de solo e da integração de parâmetros morfométricos, topográficos, hidrológicos e de uso/cobertura da terra no estado do Rio de Janeiro, Brasil. Ambi-Agua, Taubaté, v. 4, n. 1, p. 93-116, 2009. (doi:10.4136/ambi-agua.76)

Tabela 5. Grau de associação entre os parâmetros da equação universal de perda de solo e da vulnerabilidade de sub-bacias.

\begin{tabular}{clc}
\hline Parâmetros USLE & Parâmetros Vulnerabilidade Sub-bacia & Correlação Sperman \\
\hline R & - & \\
K & - & 0,99 \\
LS & DECL & 0,90 \\
LS & DPALT & $-0,64$ \\
C & COBVEG & 0,61 \\
C & AGRIC & 0,26 \\
C & PAST & $-0,09$ \\
C & URBAN & \\
- & DD & \\
- & IC & \\
- & RUNOFF & \\
\hline
\end{tabular}

Já o parâmetro topográfico LS médio da sub-bacia, tem alta correlação com a declividade percentual média (Figura 13), diferente do desvio padrão da altitude, que apresenta maior dispersão (Figura 14), significando que o fator LS pode ser substituído por uma variável de fácil obtenção quando o objetivo for um indicador topográfico para a sub-bacia.

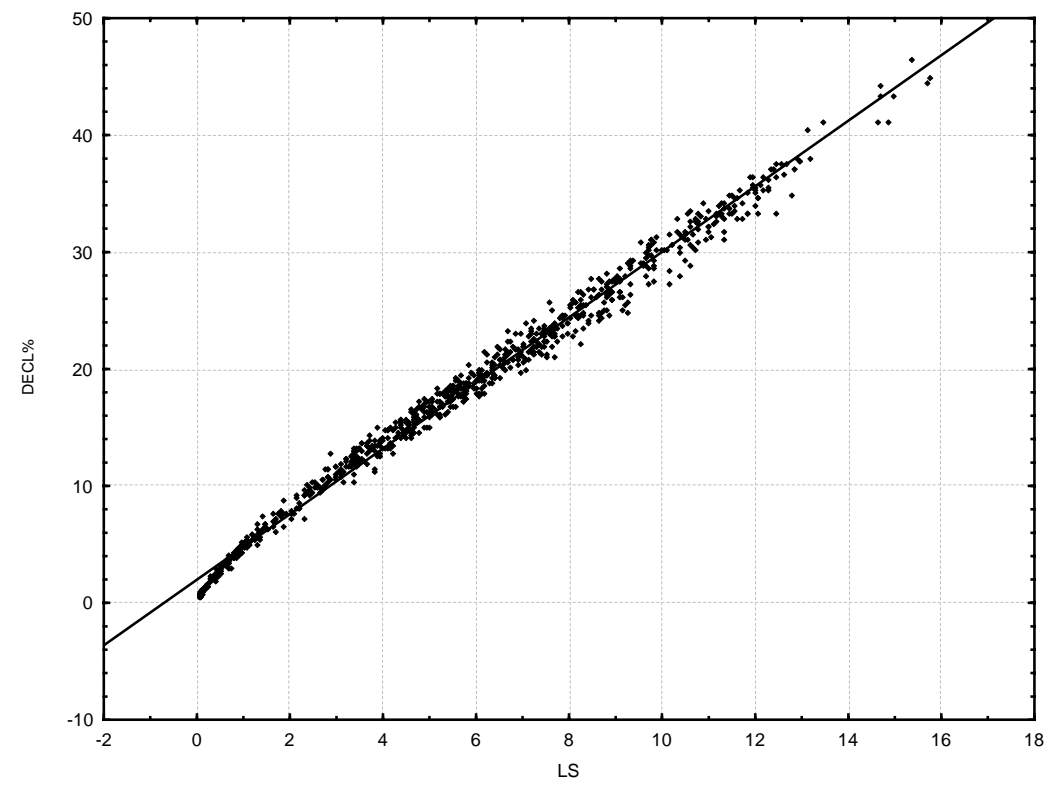

Figura 13. Dispersão entre o fator LS médio por sub-bacia e a declividade percentual média (DECL).

O parâmetro C é uma inferência do grau de proteção do solo de acordo com a classe de uso/cobertura de forma que, quanto menor, maior a proteção. Para o índice de vulnerabilidade, as classes têm pesos iguais, sendo o grau de proteção do solo dado pela proporção da classe na bacia. Existe uma correlação da proporção de classes de uso/cobertura da terra com o fator $\mathrm{C}$ médio por sub-bacia, expressa por linhas de tendência que representam bacias com aumento gradativo do uso por pastagens em substituição a cobertura, do aumento gradativo da área agrícola, e uma zona intermediária com bacias que não seguem esse padrão (Figura 15). 
COSTA, T. C. C.; FIDAlgO, E. C. C.; NAIME, U. J.; GUIMARÃES, S. P.; ZARONI, M. J.; UZEDA, M. C. Vulnerabilidade de sub-bacias hidrográficas por meio da equação universal de perda de solo e da integração de parâmetros morfométricos, topográficos, hidrológicos e de uso/cobertura da terra no estado do Rio de Janeiro, Brasil. Ambi-Agua, Taubaté, v. 4, n. 1, p. 93-116, 2009. (doi:10.4136/ambi-agua.76)

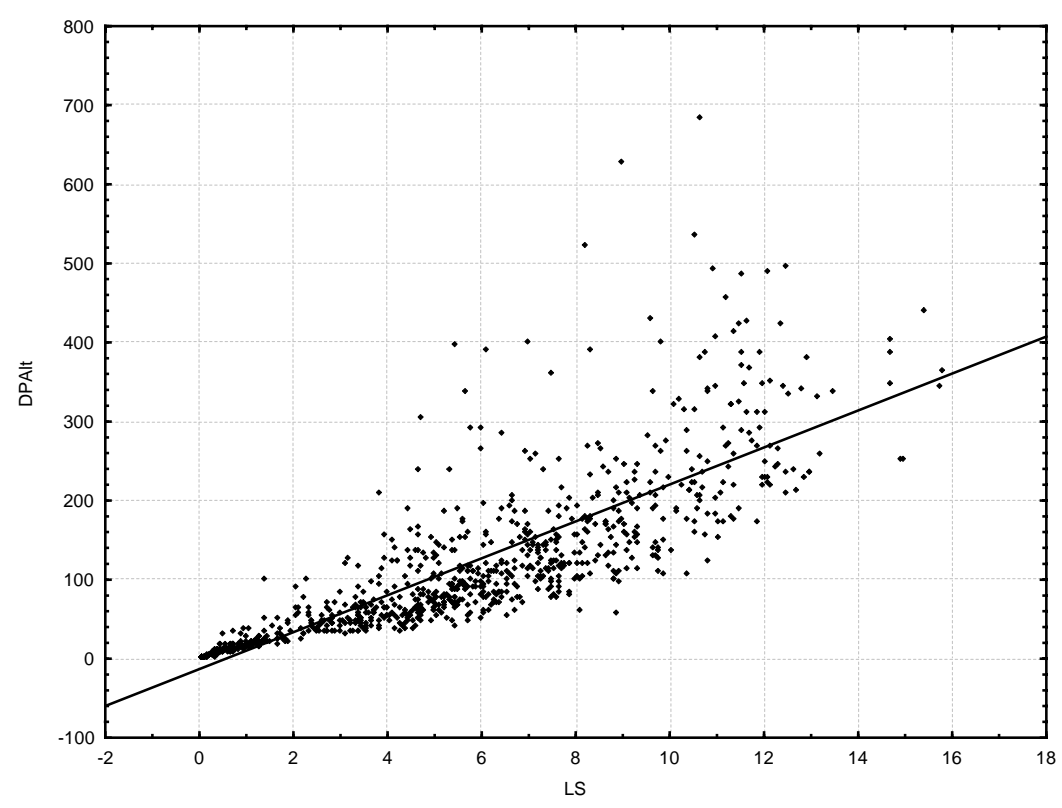

Figura 14. Dispersão entre o fator LS médio por sub-bacia e o desvio-padrão da altitude (DPALT).

Com relação à cobertura vegetal, a linha de tendência mostra um grande número de bacias com gradação da redução da cobertura substituída pela pastagem, e um número relativamente pequeno de bacias que apresentam esse comportamento para áreas agrícolas (Figura 16).

Verifica-se assim a associação do parâmetro da USLE com o critério de proporção da classe de uso/cobertura da terra, podendo-se ainda integrá-los na aplicação por sub-bacia, multiplicando a proporção da classe pelo fator C.

Os demais parâmetros, morfométricos (densidade de drenagem, índice de circularidade), e hidrológico (runoff) são exclusivos ao método de vulnerabilidade de sub-bacias.

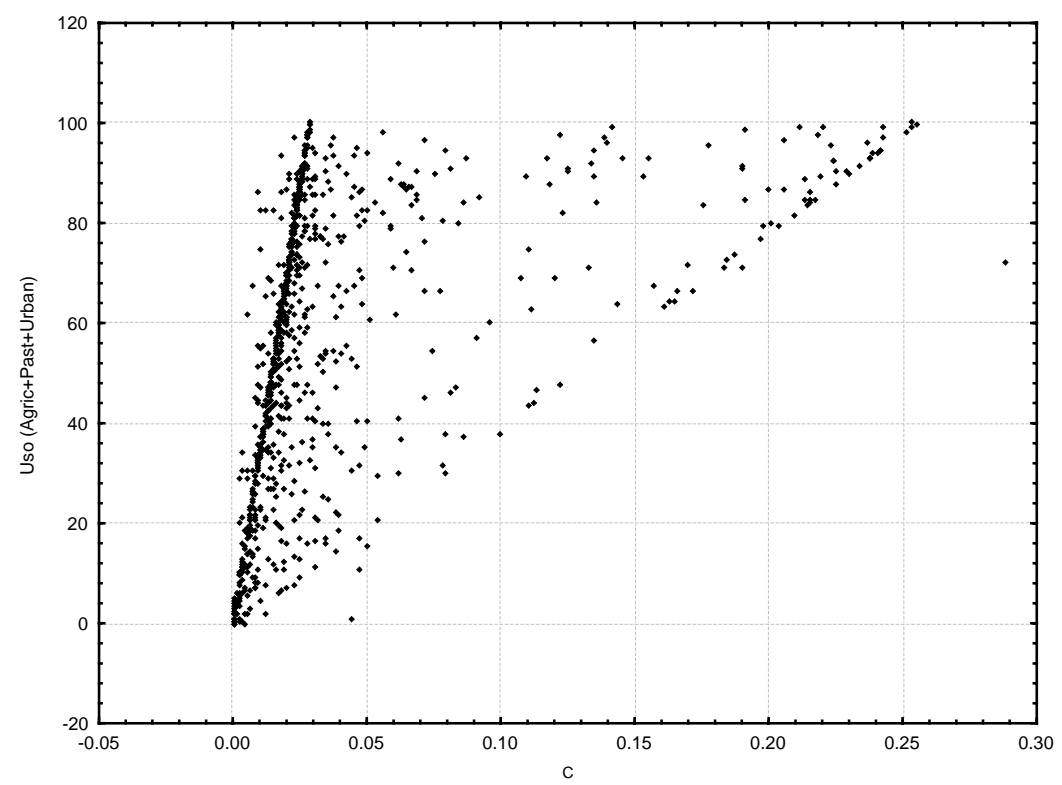

Figura 15. Dispersão do Uso da Terra (soma das proporções de áreas agrícolas, urbanas e pastagens na sub-bacia) em função da média de fatores $\mathrm{C}$ na sub-bacia. 
COSTA, T. C. C.; FIDAlgO, E. C. C.; NAIME, U. J.; GUIMARÃES, S. P.; ZARONI, M. J.; UZEDA, M. C. Vulnerabilidade de sub-bacias hidrográficas por meio da equação universal de perda de solo e da integração de parâmetros morfométricos, topográficos, hidrológicos e de uso/cobertura da terra no estado do Rio de Janeiro, Brasil. Ambi-Agua, Taubaté, v. 4, n. 1, p. 93-116, 2009. (doi:10.4136/ambi-agua.76)

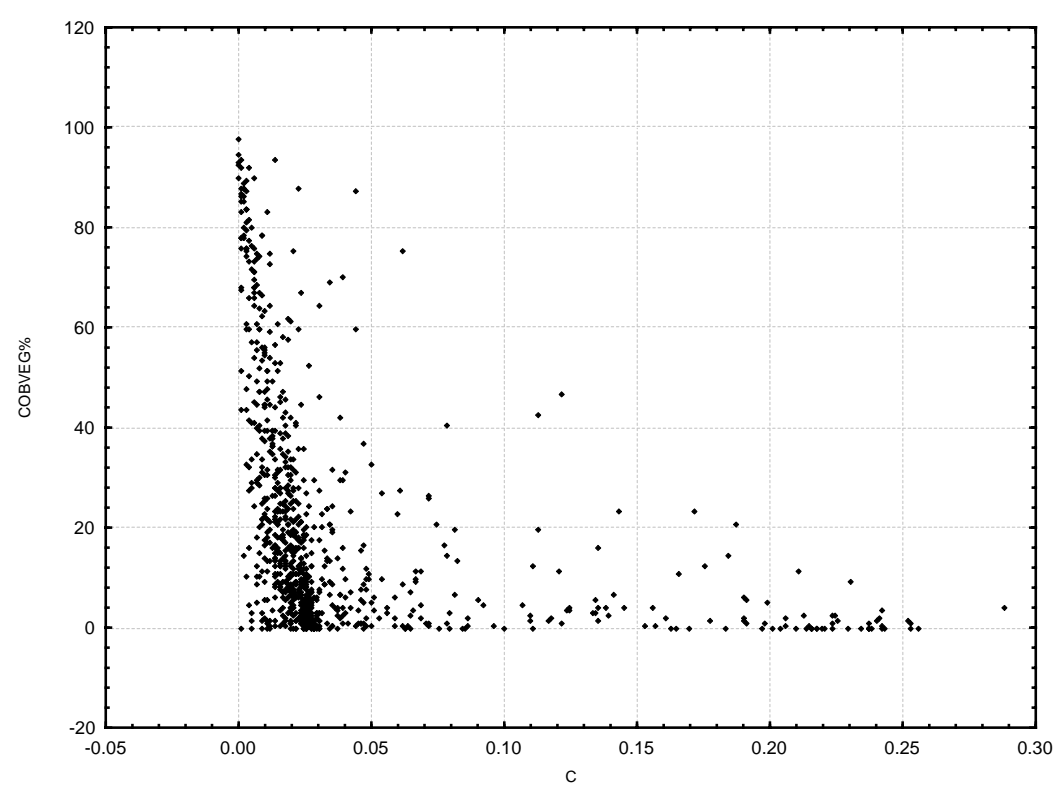

Figura 16. Dispersão da proporção da cobertura vegetal em função da média de fatores $\mathrm{C}$ na sub-bacia.

Ao comparar os resultados de ambos os métodos (Figura 17), constata-se fraca associação, embora significativa, devido aos parâmetros exclusivos de cada método, por não apresentarem parâmetros completamente compatíveis, e originarem de resoluções diferentes (pixel e sub-bacia), sendo esse um resultado favorável ao desenvolvimento de uma metodologia integrada de inferência sobre a vulnerabilidade em sub-bacias.

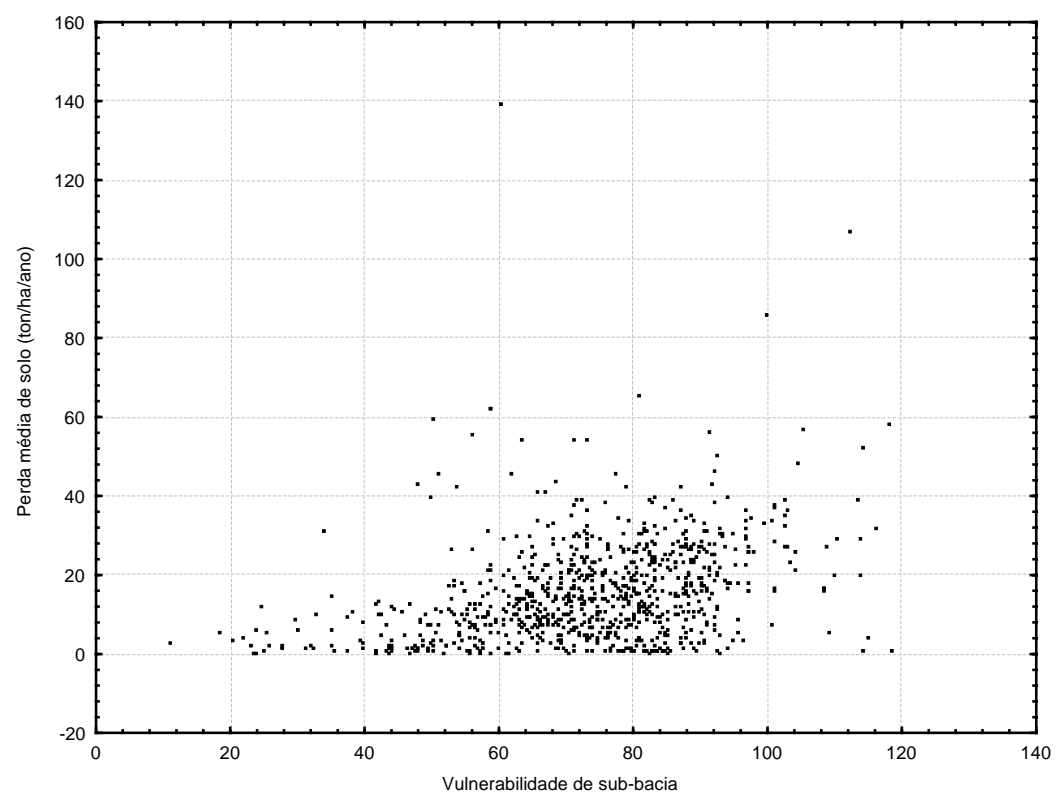

Figura 17. Dispersão da perda média de solo por sub-bacia $(\mathrm{Mg} / \mathrm{ha}$.ano) em função do índice de vulnerabilidade de sub-bacia ( $\mathrm{n}=883$, Correlação de Spearman=0,367, $\mathrm{p}<0,0000001)$.

Ambos os métodos indicaram no noroeste, sub-bacias críticas nos municípios de São Fidelis, Cambuci e São Sebastião do Alto. Na região norte, apenas o método de vulnerabilidade indicou o centro leste de Campos dos Goytacazes e o norte de São Francisco 
de Itabapoana, devido ao relevo suave e ao efeito da variável de fluxo hídrico. O mesmo ocorreu para a bacia da baía de Guanabara, com sub-bacias críticas nos municípios de Itaboraí, São Gonçalo, porção leste de Duque de Caxias, São João de Meriti, Nova Iguaçu, Seropédica, Itaguaí, Queimados e Rio de Janeiro, que, embora, não sujeitas às perdas de solo de grande magnitude, têm o efeito dos fatores de uso da terra, principalmente áreas urbanas.

No vale do Paraíba, as sub-bacias mais vulneráveis estão em Resende, Barra Mansa, Volta Redonda e Quatis, ao norte do município de Cantagalo, e ao noroeste de Sapucaia. Um estudo do risco de erosão do solo para Volta Redonda foi obtido por Dias et al. (2001), concluindo que fatores antrópicos induziram a proliferação de áreas com instabilidade ambiental. Os resultados não serão sempre concernentes com as evidências de degradação na sub-bacia, pela complexidade de fatores extrínsecos aos modelos, como históricos de exploração da terra, podendo-se citar, por exemplo, a cultura do café no vale do Paraíba no período do Brasil Império, que levou a exaustão das terras. Os modelos indicam o potencial de degradação da sub-bacia.

A região dos lagos, também por pressão urbana, foi indicada pelo índice de vulnerabilidade com sub-bacias mais vulneráveis ao sudeste de Saquarema, oeste de Maricá, região central de Araruama e ao norte de Cabo Frio.

Visando à mitigação da degradação e à recuperação ambiental em sub-bacias com predominância da atividade agropecuária, sistemas de produção sustentável podem ser implementados, como os agroflorestais, plantio direto, sistema integração lavoura-pecuária para a recuperação de pastagens degradadas, dentre outros. Sub-bacias em áreas de grande importância biológica e próximas de Unidades de Conservação podem ser integradas às estratégias de serviços ambientais e corredores de biodiversidade. E sub-bacias muito vulneráveis e com inadequação frente à legislação ambiental, devem ser prioritárias para os órgãos de fiscalização ambiental e para programas de recuperação florestal.

\section{CONCLUSÕES}

Parâmetros topográficos e de uso/cobertura da terra da equação universal de perda de solo se correlacionam com os da metodologia de vulnerabilidade de sub-bacias. Parâmetros edáficos, climáticos, hidrológicos e morfométricos são complementares entre os métodos. Conclui-se que a USLE e o índice de vulnerabilidade podem integrar uma metodologia para analisar vulnerabilidade de sub-bacias.

\section{AGRADECIMENTOS}

Agradecemos à Fundação CIDE, ao Instituto Biomas, à Fundação SOS Mata Atlântica, à SERLA, pelo fornecimento de dados e sugestões, também ao pesquisador José Francisco Lumbreras, e ao Critical Ecosystem Partership Fund (CEPF), Conservação Internacional (CI) e Rede para Conservação da Mata Atlântica, pelo apoio financeiro ao Projeto "Estratégias e Ações para Conservação da Mata Atlântica do Estado do Rio de Janeiro", de onde se originou este trabalho. 


\section{REFERÊNCIAS}

AGÊNCIA NACIONAL DE ÁGUAS - ANA. Disponível em: $<$ http://www.hidroweb.ana.gov.br>. Acesso em: 14 abril de 2005.

ALFONSI, R. R.; PINTO, H. S.; ZULLO JÚNIOR, J.; CORAL, G.; ASSAD, E. D.; EVANGELISTA, B. A. et al.. Zoneamento climático da cultura do café (Coffea Arabica) no Estado do Rio de Janeiro. 2003. Disponível em: http://www.cpa.unicamp.br/cafe/RJ_menu.html. Acesso em: 14 abril de 2005.

BACCHI, O. O. S.; REICHARD, K.; SPAROVEK, G.; RANIERI, S. B. L. Soil erosion e valuation in a small watershed in Brazil through 137Cs fallout redistribution analysis and conventional models. Acta Geologica Hispanica, Barcelona, v. 35, n. 3-4, p. 251 $259,2000$.

BERTONI, J.; LOMBARDI NETO, F. Conservação do solo. Piracicaba: Ícone, 1985. 392p.

BRASIL. Lei $n^{0}$ 4771, de 15 de setembro de 1965. Institui o Novo Código Florestal. Disponível em < http://www.cetesb.sp.gov.br>. Acesso em: 12 fevereiro de 2009.

BRITO, J. L. S.; LIMA, S. C.; SHIKI, S.; MOREIRA, M. R. Uso do Geoprocessamento na estimativa da perda de solos por erosão laminar em Irai de Minas-MG. In: SIMPÓSIO BRASILEIRO DE SENSORIAMENTO REMOTO (SBSR), 9., 1998, Santos. Anais... São José dos Campos: INPE, 1998. p. 501-512. 1 CD-ROM.

BUENO, C. R. P.; STEIN, D. P. Potencial natural e antrópico de erosão na região de Brotas, Estado de São Paulo. Acta Scientiarum. Agronomy, Maringá, v. 26, n. 1, p. 1-5, 2004.

CARVALHO FILHO, A. dE; LUMBRERAS, J. F.; WITTERN, K. P.; LEMOS, A. L.; SANTOS, R. D. dos; CALDERANO FILHO, B. et al.. Levantamento de reconhecimento de baixa intensidade dos solos do estado do Rio de Janeiro. Rio de Janeiro: Embrapa Solos, 2003a. Contém texto e mapa color. Escala 1:250.000. (Embrapa Solos. Boletim de Pesquisa e Desenvolvimento, 32). No prelo.

CARVALHO FILHO, A. E; LUMBRERAS, J. F.; WITTERN, K. P.; LEMOS, A. L.; SANTOS, R. D. dos; CALDERANO FILHO, B. et al. Mapa de reconhecimento de baixa intensidade dos solos do estado do Rio de Janeiro. Rio de Janeiro: Embrapa Solos, 2003b. 1 mapa, color. Escala 1:250.000. Disponível em: $<$ http://www.cnps.embrapa.br/solosbr/sigweb.html >. Acesso em: 14 de abril de 2005.

CARVALHO JÚNIOR, W. Modelos de planejamento agrícola conservacionista com suporte de geoprocessamento: estudo de caso, municípios de Paty de Alferes e Miguel Pereira - RJ. 1985. 104f. Dissertação (Mestrado em Geoprocessamento) - Universidade Federal do Rio de Janeiro, Rio de Janeiro, 1985.

COLLARES, E. G. Avaliação de alterações em redes de drenagem de sub-bacias como subsídio ao zoneamento geoambiental de bacias hidrográficas: Aplicação na bacia hidrográfica do Rio Capivari-SP. 2000. 211f. Tese (Doutorado em ) - Universidade de São Carlos, Campinas, 2000. 
COSTA, T. C. C.; SOUZA NETO, N. C.; OLIVEIRA, M. A. J.; ACCIOLY, L. J. O. Estimativa da diversidade florística da caatinga por meio da análise multicriterial. In: SIMPÓSIO BRASILEIRO DE SENSORIAMENTO REMOTO (SBSR), 11., 2003, Belo Horizonte. Anais... São José dos Campos: INPE, 2003. p. 2689-2696. 1 CD-ROM.

COSTA, T. C. C.; UZEDA, M. C.; FIDALGO, E. C. C.; LUMBRERAS, J. F.; ZARONI, M. J.; NAIME, U. J. et al. Vulnerabilidade ambiental em sub-bacias hidrográficas do Estado do Rio de Janeiro por meio de integração temática da perda de solo (USLE), variáveis morfométricas e o uso/cobertura da terra. In: SIMPÓSIO BRASILEIRO DE SENSORIAMENTO REMOTO (SBSR), 13., 21-26 abril 2007, Florianópolis. Anais... São José dos Campos: INPE, 2007. p. 2493-2500. 1 CD-ROM.

DIAS, J. E.; GOMES, O. V. O.; GOES, M. H. B. Áreas de riscos de erosão do solo: uma aplicação por geoprocessamento. Floresta e Ambiente, Seropédica, v. 8, n. 1, p. 1-10, 2001.

EASTMAN, J. R. IDRISI Source Code 1987-2003. Worcester: Clark University, 2003. 1 v.

EASTMAN, J. R.; JIN, W.; KYEM, P. A. K.; TOLEDANO, J. Raster procedures for multicriteria, multi-objetive decisions. Photogrammetric Engineering and Remote Sensing, Bethesda, v. 61, n. 5, p. 539-547, 1995.

FIGUEIREDO, D. G. Análise de Fourier e equações diferenciais parciais. Rio de Janeiro: Instituto de Matemática Pura e Aplicada, CNPq, 1977. 274p. (Projeto Euclides).

FLANAGAN, D. C.; NEAREING, M. A. USDA - Water erosion prediction project: hillslope profile and watershed model documentation. West Lafayette: NSERL, 1995. Report n.10.

FULLER, D.; JEFFE, M.; WILLIAMSON, R. A.; JAMES, D. Satellite remote sensing and transportation lifelines: safety and risk analysis along rural Southwest roads. 2002. Disponível em: <http://www.isprs.org/commission1/proceedings/paper/00089.pdf $>$. Acesso em: 06 maio de 2005.

FUNDAÇÃO CENTRO DE INFORMAÇÕES E DADOS DO RIO DE JANEIRO (CIDE). Índice de qualidade dos municípios - verde (IQM - Verde). Rio de Janeiro: CIDE, 2000. 1 CD-ROM.

FUNDAÇÃO SOS MATA ATLÂNTICA E INSTITUTO NACIONAL DE PESQUISAS ESPACIAIS - INPE. Atlas dos remanescentes florestais da Mata Atlântica: período 1995-2000. Relatório Final. Disponível em: <HTTP://www.rma.org.br >. Acesso em: 12 de fevereiro de 2009.

GALDINO, S.; RISSO, A.; SORIANO, B. M. A.; VIEIRA, L. M.; PADOVANI, C. R.; POTT, A. et al. Perdas de solo na Bacia do Alto Taquari - Corumbá: Embrapa Pantanal. Boletim de Pesquisa e Desenvolvimento, n. 44, p. 40, 2003.

GIBOSHI, M. L. Desenvolvimento de um sistema especialista para determinar a capacidade de uso da terra. 1999. 77f. Dissertação (Mestrado em Planejamento e Produção Agropecuária) - Faculdade de Engenharia Agrícola, Universidade Estadual de Campinas, Campinas, 1999. 
COSTA, T. C. C.; FIDAlGO, E. C. C.; NAIME, U. J.; GUIMARÃES, S. P.; ZARONI, M. J.; UZEDA, M. C. Vulnerabilidade de sub-bacias hidrográficas por meio da equação universal de perda de solo e da integração de parâmetros morfométricos, topográficos, hidrológicos e de uso/cobertura da terra no estado do Rio de Janeiro, Brasil. Ambi-Agua, Taubaté, v. 4, n. 1, p. 93-116, 2009. (doi:10.4136/ambi-agua.76)

INSTITUTO BRASILEIRO DE GEOGRAFIA E ESTATÍSTICA - IBGE. Folhas SF 23/24 Rio de Janeiro / Vitória: geologia, geomorfologia, pedologia, vegetação, uso potencial da terra. Rio de Janeiro: IBGE, 1983. 775 p. (Levantamento de Recursos Naturais, 32).

JANSON, S.; DOMINGUE, J. Extracting topographic structure from digital elevation data for geographic information system analysis. Photogrammetric Engineering and Remote Sensing, Bethesda, v. 54, n. 11, p. 1593-1600, 1988.

JENSEN, J. R. Introductory digital image processing: a remote sensing perspective. 2 ed. Englewood-Cliffs: Prentice Hall, 1996. 1996. 316p. (Prentice Hall series in geographic information science).

LONGHI, A. L. B.; MENESES, P. R. O uso de técnicas de geoprocessamento e sensoriamento remoto para o zoneamento de Florestas Nacionais. In: SIMPÓSIO BRASILEIRO DE SENSORIAMENTO REMOTO (SBSR), 12., 16-21 abril 2005, Goiânia. Anais... São José dos Campos: INPE, 2005. p. 2245-2250 1 CD-ROM.

MENDES, J. F. G.; MOTIZUKI, W. S. Urban quality of life evaluation scenarios: the case of São Carlos in Brazil. CTBUH Review, v. 1, n. 2, p. 13-23, 2001.

MILANI, J. R.; CANALI, N. E. O sistema hidrográfico do rio Matinhos: uma análise morfométrica. R. RA'EGA, Curitiba, n. 4, p. 139-152, 2000.

MOREIRA SÁ, A.; LIMA, J. M.; CURI, N.; MASSAROTO, J. A. J. J.; MARQUES, G. S. M. Estimativa da erodibilidade pela desagregação por ultra-som e atributos de solos com horizonte B textural. Pesquisa Agropecuária Brasileira, Brasília, v. 39, n. 7, p. 691699, jul. 2004.

NATIONAL AERONAUTICS AND SPACE ADMINISTRATION - NASA. Homepage. Disponível em: <https://zulu.ssc.nasa.gov/mrsid/mrsid.pl>. Acesso em: 01 de março de 2005.

PARANHAS FILHO, A. C.; FIORI, A. P.; DISPERATI, L.; LUCCHESI, C.; CIALI A.; LASTORIA G. Avaliação multitemporal das perdas de solos na bacia do rio Taquarizinho-MS. Boletim Paranaense de Geociências, Curitiba, n. 52, p. 49-59, 2003.

PEBESMA, E. J. Gstat, a program for geostatistical modelling, prediction and simulation. 1998. Disponível em: <http://www.gstat.org>. Acesso em: 22 de fevereiro de 2009.

PIMENTA M. T. Caracterização da Erodibilidade dos Solos a Sul do Rio Tejo. Disponível em: <http://snirh.inag.pt/snirh/estudos_proj/portugues/docs/ desertificacaofichas.html>. Acesso em: 19 set. 2005a.

PIMENTA M. T. Directrizes para a Aplicação da Equação Universal de Perda dos Solos em SIG. Disponível em: <http://snirh.inag.pt/snirh/estudos_proj/portugues/docs/ desertificacaofichas.html>. Acesso em: 19 set. 2005 b.

RENARD, K. G.; FOSTER, G. R.; WEESIES, G. A.; McCOOL, D. K.; YODER, D. C. Predicting soil erosion by water: a guide to conservation planning with the revised universal soil loss equation (RUSLE) - Agricultural handbook, 703. Washington: USDA-ARS, 1997. 384p. 
RIBEIRO, J. C.; SALOMÃO, F. X. T. Abordagem morfopedológica aplicada ao diagnóstico e prevenção de processos erosivos na bacia hidrográfica do alto rio da casca, MT São Paulo, UNESP. Geociências, Rio Claro, v. 22, n. 1, p. 83-95, 2003.

ROCHA, J. S. M. Manual de manejo integrado de bacias hidrográficas. Santa Maria: UFSM, 1991. 181p.

SANTOS, P. R. A.; GABOARDI, C.; OLIVEIRA, L. C. Avaliação da precisão vertical dos modelos SRTM para a Amazônia. In: SIMPÓSIO BRASILEIRO DE SENSORIAMENTO REMOTO (SBSR), 12., 16-21 abril 2005, Goiânia. Anais... São José dos Campos: INPE, 2005. p. 4473-4480. 1 CD-ROM

SIEGEL, S. Nonparametric statistics for the behavioral sciences. New York: McGrawHill, 1956. $350 \mathrm{p}$.

SILVA, V. C. Estimativa da erosão atual da bacia do Rio Paracatu (MG / GO / DF). Pesquisa Agropecuária Tropical, Goiânia, v. 34, n. 3, p. 147-159, 2004.

TEIXEIRA A. J. A; CRUZ C. B. M. Classificação de bacias de drenagem com o suporte do sensoriamento remoto e geoprocessamento- o caso da Baía de Guanabara. In: SIMPÓSIO BRASILEIRO DE SENSORIAMENTO REMOTO (SBSR), 12., 16-21 abril 2005, Goiânia. Anais... São José dos Campos: INPE,2005. p. 2779-2786. 1 CDROM.

VASQUEZ-FERNANDES, G. A; FORMAGGIO, A. R.; EPIPHANIO, J. C. N.; GLERIANI, J. M. Determinação de sequências culturais em microbacia hidrográfica para caracterização do fator $\mathrm{c}$ da EUPS, utilizando fotografia aérea. In: SIMPÓSIO BRASILEIRO DE SENSORIAMENTO REMOTO (SBSR), 8., 14-19 abril 1996, Goiânia. Anais... São José dos Campos: INPE, 1996. p. 63-67 1 CD-ROM

WISCHMEIER, W. H.; SMITH, D. D. Predicting rainfall erosion losses: a guide to conservation planning. Washington: USDA, 1978. 57 p. (Agricultural Handbook, 537). 